\title{
ESTIMACIÓN DE LA VULNERABILIDAD DE LOS MUNICIPIOS TURÍSTICOS DE JALISCO ANTE LA PANDEMIA DEL COVID-19 Y OPCIONES DE POLÍTICA PÚBLICA
}

\author{
BASILIO VERDUZCO CHÁVEZ \\ basiliov@cucea.udg.mx \\ Universidad de Guadalajara, Jalisco, México
}

Este artículo propone un modelo general tridimensional para estimar la vulnerabilidad de los destinos turísticos ante la pandemia del COVID-19. El modelo se aplica con datos de municipios de Jalisco, México, con el propósito de explorar opciones de políticas públicas. Relacionando resultados y niveles de incidencia se presenta una tipología de municipios útil para el diseño de políticas ad hoc, considerando vulnerabilidades y patrones de contagio en municipios metropolitanos, costeros de turismo rural, ribereños, pueblos mágicos, turismo religioso y ciudades medias. La principal contribución es el desarrollo de un modelo replicable para explorar opciones de políticas dirigidas a enfrentar la vulnerabilidad.

Palabras clave: pandemia del COVID-19, vulnerabilidad, resiliencia turística, municipios de Jalisco, modelo multiatributo.

\section{ESTIMATING THE VULNERABILITY OF THE TOURIST MUNICIPALITIES OF JALISCO TO THE COVID-2019 PANDEMIC AND PUBLIC POLICY OPTIONS}

This article proposes a general three-dimensional model to estimate the vulnerability of tourist destinations to the COVID-19 pandemic. The model is applied with data for municipalities in Jalisco, Mexico, with the purpose of exploring public policy options. Relating results and levels of incidence, a typology of municipalities, useful for the design of ad hoc policies, is presented considering vulnerabilities and contagion patterns distinguishing metropolitan municipalities from those located in coastal rural, riverside, magical towns, religious tourism and medium size cities. The main contribution is the development of a replicable model to explore policy options aimed to addressing vulnerability.

Keywords: COVID-19 pandemic, vulnerability, tourist resilience, municipalities in Jalisco, multi-attribute model. 


\section{Introducción}

$\square$ I objetivo general de este trabajo es proponer y aplicar un modelo de estimación de vulnerabilidad de economías locales a nivel municipal, así como relacionar dicho indicador con los patrones de contagio del COVID-19, lo que permite explorar opciones de política por tipo de municipio. Se aplica un concepto operacional de vulnerabilidad ante la pandemia, considerando las medidas de distanciamiento social, en referencia a circunstancias observadas en las economías a estudiar, que pueden contribuir a agudizar los impactos inmediatos y futuros de la enfermedad, así como poner a prueba su resiliencia.

La aplicación del modelo se enfoca en municipios del estado de Jalisco, México. Los resultados obtenidos son analizados a la luz de los patrones de incidencia en las municipalidades con mayor actividad turística, entre las que se encuentran Puerto Vallarta, Guadalajara, Zapopan, La Huerta, Mazamitla, Tapalpa y Chapala.

La resiliencia turística es una construcción socioespacial colectiva, con variaciones entre sitios, forjada mediante un proceso que involucra acciones públicas y privadas. Como otros asuntos sociales complejos, la resiliencia no avanza en una sola dirección, los destinos turísticos pueden ganarla o perderla. Cada región del mundo, cada espacio urbano o rural, enfrenta condiciones que demandan acciones específicas.

Para analizar el caso de los municipios turísticos de Jalisco, este artículo se organiza como sigue: en la primera parte se revisa literatura sobre vulnerabilidad y se ofrecen datos del turismo en Jalisco. Enseguida, se presenta un modelo analítico tridimensional para estimar la vulnerabilidad de economías locales. La tercera parte muestra resultados de tres estimaciones de la vulnerabilidad en los municipios turísticos analizados. La cuarta, presenta una tipología de las municipalidades y sus problemas ante el COVID-19. En la quinta sección se exploran lineamientos de políticas y procesos de implementación. Finalmente, se presentan las conclusiones. 


\section{Vulnerabilidad y resiliencia ante el COVID-19 en destinos turísticos}

Por décadas, los conceptos de vulnerabilidad y resiliencia de los destinos turísticos han estado presentes en los estudios afines y en la literatura de política pública local (Montaño et al., 2017; Xu et al., 2017). Estos trabajos tienden a considerar ambos conceptos como estrechamente relacionados; para evaluarlos, consideran elementos como los patrones de integración, convivencia económica y social, la gobernanza, gestión del riesgo, preparación y respuesta. En ellos se distinguen etapas que incluyen protección, reacción inmediata, recuperación básica y reconstrucción (Huitraleo et al., 2019).

Una vertiente de trabajos estudia la vulnerabilidad y resiliencia ante catástrofes y fenómenos naturales, e identifica secuencias de acción (Rodríguez-Toubes y Álvarez, 2013; Proaño et al., 2018). Otros analistas abordan problemas espacial y temporalmente fluidos como son la inseguridad, las crisis de salud o la violencia (Cheer y Lew, 2018). Algunos más enfatizan la necesidad de intervenir en las condiciones generales de vida de la población para ganar resiliencia (Malik, 2014), o en las interconexiones entre gente, recursos ambientales, espacio y tiempo (Student et al., 2020).

Diversos trabajos usan como referente la amenaza de desastres naturales o el cambio climático. La crisis del COVID-19 ha cambiado esa situación, a medida que más expertos se han interesado en los impactos globales, nacionales, y locales de la pandemia o sus consecuencias en el turismo (Gössling et al., 2020; OECD, 2020; Foo et al., 2020; Gopalakrishnan et al., 2020).

Resiliencia y vulnerabilidad se pueden estudiar a distinta escala, para múltiples fines y usando diferentes mediciones contextualmente relevantes. En este artículo se les estudia a nivel municipal, usando un concepto operacional de vulnerabilidad de economías locales que recupera tanto la noción, definida en términos de riesgos de afectación negativa derivada de un impacto o shock (Johnson, 2006; Briguglio et al., 2009; Batista et al., 2018), como los riesgos asociados a la dependencia del turismo, que dificultan la instrumentación de respuestas ante cambios estructurales acelerados (Pitarch-Garrido, 2020).

En cuanto al concepto de resiliencia, se toma como eje la capacidad de respuesta, que considera diversos aspectos necesarios para inducir "la recuperación temprana de la normalidad del sistema turístico, renovado y con la capacidad de creación de 
riqueza y bienestar social anterior al fenómeno disruptivo" (González y León, 2020, p. 712). Conforme a esa noción, se propone que, a mayor especialización de la economía, menor producción de bienes intermedios y alimentos, a la par de que la localización en una zona o ciudad, cuyos privilegios se convierten en carga durante una crisis, son factores que incrementan la vulnerabilidad y reducen la resiliencia de un destino, debido a dificultades para hacer ajustes en el funcionamiento de la economía local.

Las primeras reacciones ante los impactos del COVID-19 sugieren que volver a hacer negocios como en años anteriores es una opción poco viable (Cimoli, 2020; Higgins-Desbiolles, 2020; loannides y Gyimóthy, 2020). La enfermedad ha puesto en crisis el modelo de desarrollo turístico y cuestionado su resiliencia.

De los estudios que han evaluado las primeras impresiones a nivel global (OECD, 2020; OIT, 2020; Gössling et al., 2020) se infiere que hay tres campos de política que es necesario atender: a) articulación de cadenas de suministro o redes de empresas donde ocurre una división de funciones, para transitar de las materias primas al producto terminado (Zhang, 2010); b) incrustación de las actividades de turismo en la vida de las comunidades, mejorando la distribución de beneficios y costos, generando formas consensuadas para disminuir los conflictos de intereses; c) aligeramiento de cargas derivadas de los costos de localización en un contexto de fuerte competencia, globalización y crisis.

El COVID-19 y la política de distanciamiento social con la que se le ha enfrentado, la cual abarca acciones que van desde la simple invitación "quédate en casa", hasta la suspensión de actividades públicas y privadas, constituyen eventos concatenados que tendrán un impacto significativo de corto, mediano y largo plazos en los destinos turísticos del mundo, incluidos, desde luego, los de Jalisco. En el corto plazo, es necesario enfrentar las consecuencias agudas, pero el mejoramiento de la resiliencia demanda una agenda de cambios de largo alcance, sensible a los contextos locales, pues no todos los municipios son iguales.

\subsection{Diversidad y concentración de la oferta de servicios turísticos en Jalisco}

En el 2018, Jalisco ocupaba el segundo lugar en México en disponibilidad de cuartos con 75 mil 422, después de Quintana Roo que tenía 102 mil 890. No obstante, ocupaba el primer lugar en número de establecimientos de hospedaje, con 2 
mil 038, casi el doble que aquel estado y sustancialmente más que Veracruz que ocupaba el segundo lugar (Sectur, s. f.). En esta oferta turística abundan unidades medianas y pequeñas que, como sugiere la Organización para la Cooperación y el Desarrollo Económicos (OECD, 2020), son menos resilientes a la pandemia.

Esta oferta se encuentra altamente concentrada en cuatro regiones: Puerto Vallarta y su zona de influencia extendida al vecino estado de Nayarit, la zona metropolitana de Guadalajara, la costa sur o costa alegre que comprende, principalmente, los municipios de Cihuatlán y La Huerta, y el lago de Chapala, en donde los servicios se concentran en los municipios de Chapala y Jocotepec. Existen además destinos de turismo de montaña y turismo religioso.

Los 30 municipios que se muestran en la tabla 1 concentran el $86 \%$ de los establecimientos de hospedaje y el $95 \%$ del personal ocupado. La oferta de hospedaje y sus efectos multiplicadores en el resto de la economía de los municipios se concentran en seis municipios: Puerto Vallarta, 33\%; Guadalajara, 29\%; Zapopan, 9\%; San Pedro Tlaquepaque, La Huerta y Cihuatlán 3\% cada uno; el resto de la entidad tiene el $20 \%$.

\subsection{Debilidades estructurales de las economías turísticas locales ante la pandemia COVID-19}

Con algunas diferencias en escala y grado de integración, el modelo de desarrollo turístico establecido en los municipios de Jalisco descansa en tres ejes típicos de la industria, que han sido identificados en las primeras evaluaciones de los impactos del COVID-19 como algunos de los más sensibles: a) una cadena de suministro desarticulada de sus áreas de influencia y altamente dependiente de abasto internacional de bienes y servicios (OECD, 2020); b) un modelo de eficiencia basado en bajos salarios y escasa distribución de beneficios a proveedores locales de bienes esenciales, incluyendo alimentos y bebidas (OIT, 2020); y c) un crecimiento basado en altas rentas de suelo, uso de transporte masivo (aéreo, terrestre y marítimo) con una fuerte dependencia de ingresos generados por flujos internacionales de viajeros (Hardingham-Gill, 2020). 
Gráfica 1. Municipios de Jalisco con personal ocupado y establecimientos de alojamiento temporal

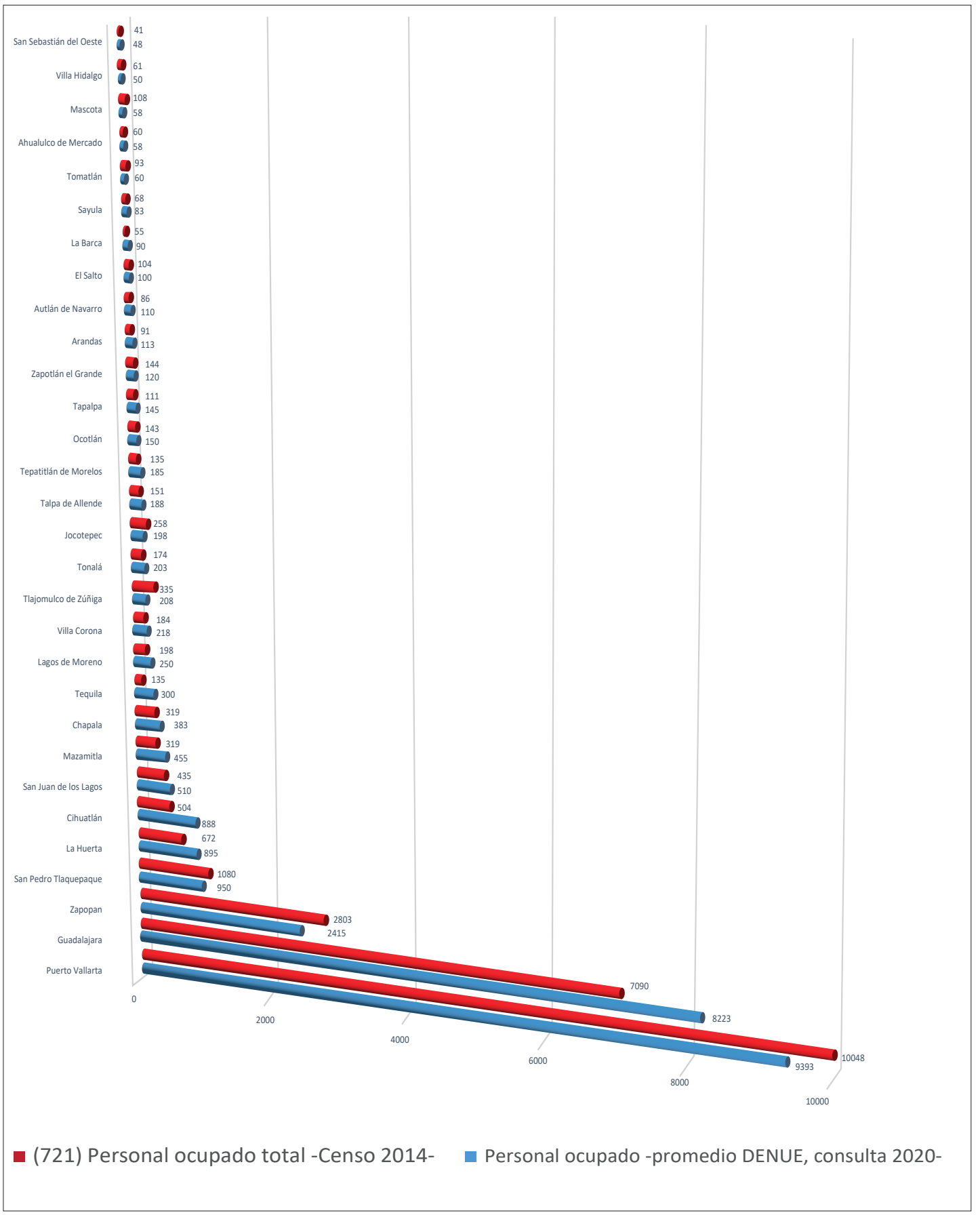

Fuente: Elaboración propia con datos del INEGI (2014 y 2020). 
En esas condiciones, la pandemia COVID-19 tiene múltiples implicaciones en las economías locales basadas en turismo, cuyas vulnerabilidades merecen atención pública para mitigar los efectos de corto plazo e incrementar la resiliencia en el largo plazo.

\section{Modelo multiatributo para estimar la vulnerabilidad de economías locales}

Los primeros reportes de daños han identificado una afectación importante en los lugares que enfrentan altas rentas y dependen fuertemente del turismo internacional (que arriba en medios de transporte masivo), así como en los barrios de los destinos turísticos que dependen directamente de ingresos del turismo y de flujos que se mueven en transporte colectivo (OECD, 2020; OIT, 2020; Gössling et al., 2020).

Este trabajo se basa en el supuesto de que las economías locales más vulnerables son aquellas que están enfrentando una caída de la demanda final, debilidad en su mezcla industrial y cargas adversas derivadas de factores de localización. Para aplicar el concepto de vulnerabilidad en el contexto del estado de Jalisco, se propone un modelo de tipo aditivo, como el explicado por Suárez Lastra et al. (2020), pero adaptado. En este caso, se usaron variables que describen aspectos estructurales de la economía y condiciones de localización, se obtienen mediciones que pueden cruzarse con indicadores de contagio o de capacidad para atender enfermos, a fin de obtener tipologías de los municipios, como población objetivo de las políticas.

La figura 1 muestra el modelo analítico con tres dimensiones que se pueden calibrar a nivel municipal, barrial o distrital. Cada eje presenta una hipótesis de mayor-menor vulnerabilidad por dimensión y se mide con el índice correspondiente. Enseguida, los resultados en cada dimensión son integrados en un índice general, usado para comparar municipios y su relación con los datos de incidencia del COVID-19. El modelo usado permite explorar soluciones de diversos tipos, como las que se muestran a continuación, formuladas como grandes objetivos de política:

a) Soluciones de saldos positivos intertemporales sostenidos (SIS). Intervenciones públicas dirigidas a enfrentar los impactos de la caída en la demanda final de servicios turísticos, y a garantizar una fluidez monetaria temporal emergente. 
Figura 1. Modelo tridimensional de vulnerabilidad de economías locales en el contexto del COVID-19

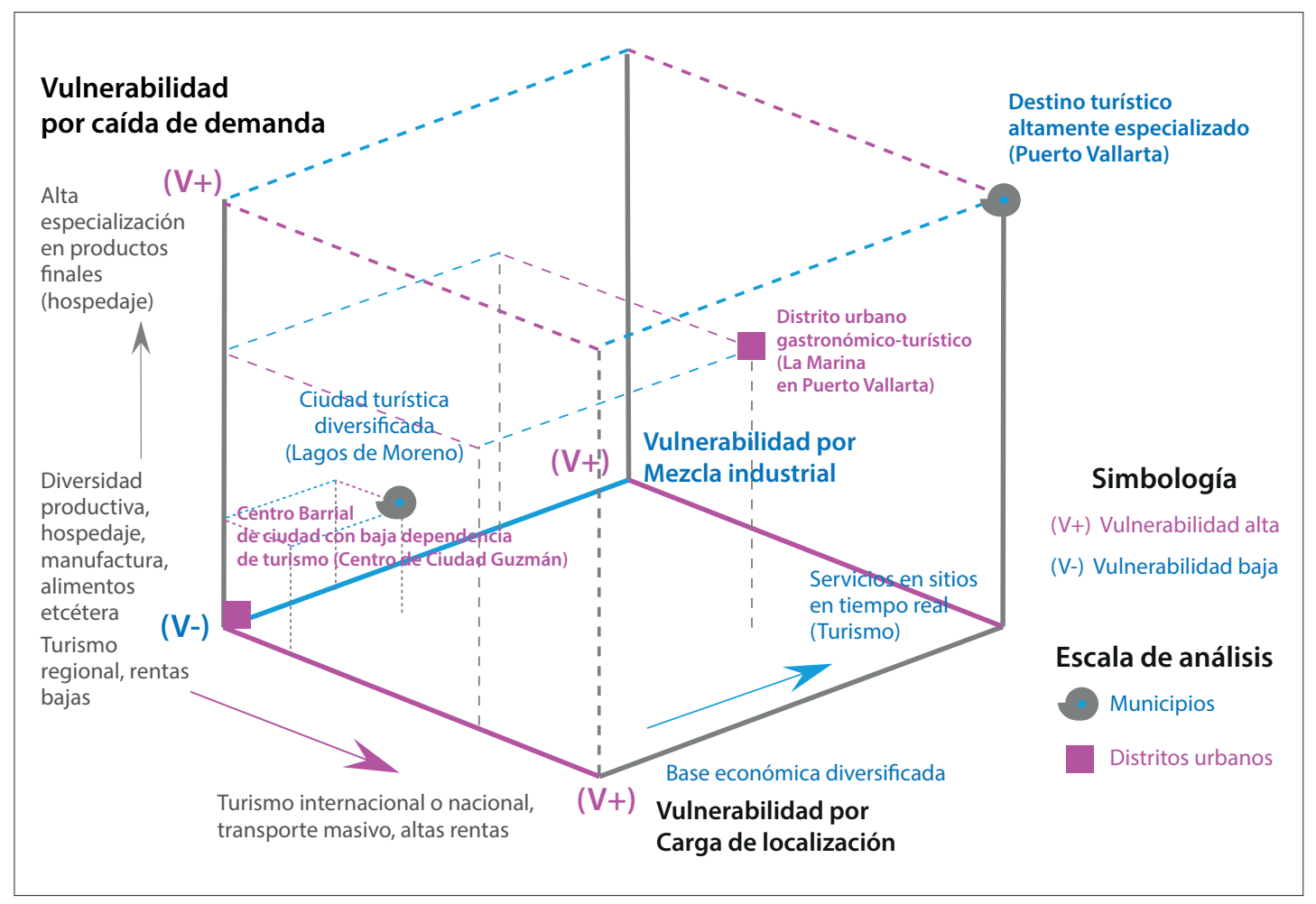

Fuente: Elaboración propia.

b) Soluciones de mezcla industrial diversificada (MID). Estas son soluciones que tienen el propósito de rescatar espacios laborales en hospedaje y alimentación, y mantener la mayor diversidad de empleos posibles en los municipios, en actividades que mitiguen la dependencia del turismo y le den funcionalidad a la economía.

c) Soluciones orientadas a la reducción de carga de localización ( $R C L$ ). Dirigidas a mitigar impactos negativos de la combinación de factores económicos adversos, asociados a localizaciones onerosas como son aquellas en suelo o fincas de altas rentas, con fuerte dependencia de los ingresos por flujos de turismo internacional y nacional movilizado en transporte masivo, donde hay mayor exposición a riesgos de infección.

Los resultados de aplicar el modelo sugerido en Jalisco se presentan enseguida. 


\section{Estimación multiatributo de la vulnerabilidad en destinos turísticos en Jalisco}

El modelo anterior sugiere que la vulnerabilidad de un destino turístico es un problema multifactorial, que se construye en tiempo y espacio determinados. En cada lugar, a distintas escalas, dicha vulnerabilidad puede ser medida para construir indicadores de acuerdo con las situaciones enfrentadas. Los resultados obtenidos muestran que es posible analizar la naturaleza multivariada del problema y usar el resultado en el diseño de políticas para enfrentar la pandemia del COVID-19 en el corto, mediano y largo plazos.

\subsection{Vulnerabilidad 1: caída de la demanda final y bajo abasto local de alimentos}

Un problema común en los destinos turísticos altamente especializados es la tendencia a desvincularse de la manufactura local de bienes finales, desplazar actividades ligadas a la producción local de alimentos y el empleo agrícola. Suelen abandonar la producción de alimentos para su población y sus visitantes, forjando cadenas de suministro remotas y dispersas, entendidas como redes de empresas que permiten vincular la producción de materias primas a los productos ofrecidos al consumidor final (Zhang, 2010; OECD, 2020).

Para estimar este indicador se usó la siguiente formula:

$$
V F A=\left(\left(V A^{*} 1000\right)+\left(R M^{*} 1000000\right)\right) /(P / E A T)
$$

En donde:

VFA $=$ Vulnerabilidad por especialización de productos finales.

$V A=$ Valor producción año agrícola (miles de pesos, 2018).

$\mathrm{RM}=$ Total remuneraciones manufactura en 2014.

$\mathrm{P}=$ Población total del municipio en 2015.

EAT = Estimación del total de empleados en establecimientos de alojamiento (subsector 721), según DENUE en 2019.

Los resultados se presentan en la tabla 1, con el comportamiento de ese indicador para 25 municipios jaliscienses con actividad hotelera de cierta importancia, cuya vulnerabilidad por caída de demanda final es mayor ${ }^{1}$. La lista está encabezada por Guadalajara, Puerto Vallarta y Zapopan, que destacan por la combinación entre su base manufacturera y su tamaño como sitios turísticos.

\footnotetext{
1 La fuente consultada no reporta valor de producción agrícola para Guadalajara, que está completamente
} urbanizado. Se introdujo un valor mínimo para hacer los cálculos y obtener un resultado utilizable. 
Entre los primeros diez lugares de vulnerabilidad se encuentran tres municipios con declaratoria de Pueblos Mágicos (Tlaquepaque, Mazamitla y Tapalpa), dos municipios de la costa sur de Jalisco (Cihuatlán y la Huerta), el principal destino de turismo religioso (San Juan de los Lagos) y Arandas como ciudad media con una importante tradición tequilera. En los siguientes diez lugares se localizan otros pueblos mágicos (Lagos de Moreno, Talpa de Allende, Mascota y Tequila), y lugares de balnearios y recreo familiar cercanos a Guadalajara, como Chapala y Villa Corona.

Tabla 1. Vulnerabilidad por caída de demanda final en municipios turísticos de Jalisco

\begin{tabular}{|c|c|c|c|c|c|}
\hline Municipio & $\begin{array}{l}\text { Población } \\
\text { total (2015) }\end{array}$ & $\begin{array}{l}\text { Empleados de } \\
\text { unidades de } \\
\text { alojamiento } \\
\text { (2019) }\end{array}$ & $\begin{array}{c}\text { Valor de } \\
\text { producción } \\
\text { (año agrícola } \\
2018 \text { miles } \\
\text { de pesos) }\end{array}$ & $\begin{array}{c}\text { Total } \\
\text { remuneraciones } \\
\text { manufactura } \\
(31-32)(2014)\end{array}$ & $\begin{array}{c}\text { Índice de } \\
\text { vulnerabilidad } \\
\text { de población } \\
\text { por caída en } \\
\text { demanda final }\end{array}$ \\
\hline Guadalajara & 1460148 & 8223 & $\left.0.011^{*}\right)$ & 31180.892 & 175598963.0 \\
\hline Puerto Vallarta & 275640 & 9393 & 232407.44 & 2417.38 & 90296957.7 \\
\hline Zapopan & 1332272 & 2415 & 408159.79 & 20074.549 & 37128860.9 \\
\hline Arandas & 7716 & 113 & 418181.15 & 336.247 & 11048520.1 \\
\hline La Huerta & 24563 & 895 & 159016.43 & 88.568 & 9021213.4 \\
\hline $\begin{array}{l}\text { San Pedro } \\
\text { Tlaquepaque }\end{array}$ & 664193 & 950 & 158388.68 & 5876.308 & 8631469.8 \\
\hline $\begin{array}{c}\text { San Juan de los } \\
\text { Lagos }\end{array}$ & 69725 & 510 & 477128.56 & 294.059 & 5640812.5 \\
\hline Cihuatlán & 41300 & 888 & 119103.02 & 126.123 & 5272656.3 \\
\hline Mazamitla & 13799 & 455 & 108989.83 & 41.457 & 4960744.0 \\
\hline Tapalpa & 19506 & 145 & 570837.55 & 33.442 & 4491978.6 \\
\hline $\begin{array}{l}\text { Lagos de } \\
\text { Moreno }\end{array}$ & 164981 & 250 & 892719.71 & 1154.786 & 3102638.6 \\
\hline Chapala & 50738 & 383 & 150435.77 & 250.209 & 3024300.2 \\
\hline $\begin{array}{c}\text { Tepatitlán de } \\
\text { Morelos }\end{array}$ & 141322 & 185 & 1196279.71 & 920.099 & 2770482.0 \\
\hline Talpa de Allende & 15126 & 188 & 176199.28 & 24.734 & 2497385.7 \\
\hline La Barca & 65055 & 90 & 1446783.67 & 152.883 & 2213050.5 \\
\hline Mascota & 14477 & 58 & 514660.7 & 29.502 & 2180108.9 \\
\hline Tequila & 42009 & 300 & 88485.34 & 174.052 & 1874864.9 \\
\hline El Salto & 183437 & 100 & 16088.87 & 3409.004 & 1867176.67 \\
\hline $\begin{array}{l}\text { Tlajomulco de } \\
\text { Zúñiga }\end{array}$ & 549442 & 208 & 596055.25 & 4218.895 & 1822775.9 \\
\hline Villa Corona & 17824 & 218 & 101624.05 & 44.621 & 1788679.3 \\
\hline
\end{tabular}


Continuación de la tabla 1

\begin{tabular}{|c|c|c|c|c|c|}
\hline Municipio & $\begin{array}{l}\text { Población } \\
\text { total (2015) }\end{array}$ & $\begin{array}{l}\text { Empleados de } \\
\text { unidades de } \\
\text { alojamiento } \\
\text { (2019) }\end{array}$ & $\begin{array}{l}\text { Valor de } \\
\text { producción } \\
\text { (año agrícola } \\
2018 \text { miles } \\
\text { de pesos) }\end{array}$ & $\begin{array}{c}\text { Total } \\
\text { remuneraciones } \\
\text { manufactura } \\
(31-32)(2014)\end{array}$ & $\begin{array}{c}\text { Índice de } \\
\text { vulnerabilidad } \\
\text { de población } \\
\text { por caída en } \\
\text { demanda final }\end{array}$ \\
\hline Ocotlán & 99461 & 150 & 448888.86 & 651.94 & 1660191.7 \\
\hline Jocotepec & 46521 & 198 & 296679.82 & 82.11 & 1612183.4 \\
\hline $\begin{array}{l}\text { Autlán de } \\
\text { Navarro }\end{array}$ & 60572 & 110 & 454756.68 & 346.423 & 1454958.8 \\
\hline $\begin{array}{c}\text { San Sebastián } \\
\text { del Oeste }\end{array}$ & 5643 & 48 & 130669.15 & 20.508 & 1285930.0 \\
\hline San Gabriel & 16105 & 23 & 813577.76 & 26.873 & 1200271.1 \\
\hline
\end{tabular}

Fuente: Estimaciones propias con base en datos del INEGI (2014, 2015 y 2020); SIAP (2020).

\subsection{Vulnerabilidad 2: baja diversidad de mezcla industrial}

El éxito del turismo se convierte en una medida de vulnerabilidad de la economía local, debido al desplazamiento de otras actividades de la mezcla industrial. Para medir la diversidad industrial se utilizó el dato que mide el efecto multiplicador del empleo en establecimientos de alojamiento temporal, un dato sencillo de medir que ilustra la diversidad de la mezcla (Gasparino et al., 2008). La fórmula usada es:

$$
I M I R=\left(M^{*}(P E A / 100) *(P E A O / 100)\right) / E A T
$$

En donde:

IMIR = Indicador de mezcla industrial resiliente.

$\mathrm{P}=$ Población total 2015.

PEA = Porcentaje de la población económicamente activa (PEA).

PEAO $=$ Porcentaje de la PEA Ocupada (encuesta 2015).

EAT $=$ Total de empleados en establecimientos de alojamiento (subsector 721).

La estimación sugiere que una baja diversificación está asociada a menor resiliencia, por lo tanto, la economía local es más vulnerable. En la tabla 2 muestra los municipios más frágiles según este indicador. Los tres municipios con la base turística menos resiliente son: La Huerta, Mazamitla y Puerto Vallarta, pero la lista de los diez menos resilientes incluye a otros cuatro pueblos mágicos: Talpa de Allende, San Sebastián del Oeste, Tequila y Tapalpa, así como Chapala y Cihuatlán. 
Tabla 2. Vulnerabilidad de los municipios turísticos de Jalisco por baja diversidad de su mezcla industrial

\begin{tabular}{|c|c|c|c|c|c|}
\hline Municipio & $\begin{array}{c}\text { Población } \\
\text { total } \\
(2015)\end{array}$ & $\begin{array}{c}\text { Población } \\
\text { Económicamente } \\
\text { Activa (PEA) }\end{array}$ & $\begin{array}{l}\text { Porcentaje } \\
\text { de PEA } \\
\text { Ocupada } \\
(2015)\end{array}$ & $\begin{array}{c}\text { Empleados de } \\
\text { establecimientos } \\
\text { de alojamiento } \\
(2020)\end{array}$ & $\begin{array}{l}\text { Vulnerabilidad por } \\
\text { caída de empleo } \\
\text { turístico. Indicador de } \\
\text { baja resiliencia por } \\
\text { mezcla industrial (IMIR) }\end{array}$ \\
\hline La Huerta & 24563 & 44.9 & 96.4 & 895 & 11.9 \\
\hline Mazamitla & 13799 & 45.4 & 97.7 & 455 & 13.5 \\
\hline Puerto Vallarta & 275640 & 54.4 & 97.1 & 9393 & 15.5 \\
\hline Cihuatlán & 41300 & 44.7 & 96.2 & 888 & 20.0 \\
\hline Arandas & 7716 & 31.1 & 96.8 & 113 & 20.6 \\
\hline $\begin{array}{c}\text { Talpa } \\
\text { de Allende }\end{array}$ & 15126 & 28.1 & 96.0 & 188 & 21.7 \\
\hline Villa Corona & 17824 & 44.3 & 97.2 & 218 & 35.2 \\
\hline Chapala & 50738 & 33.9 & 94.7 & 383 & 42.5 \\
\hline $\begin{array}{c}\text { San Sebastián } \\
\text { del Oeste }\end{array}$ & 5643 & 39.8 & 99.4 & 48 & 46.5 \\
\hline Tequila & 42009 & 41.6 & 95.7 & 300 & 55.7 \\
\hline Tapalpa & 19506 & 45.8 & 97.9 & 145 & 60.3 \\
\hline $\begin{array}{c}\text { San Juan } \\
\text { de los Lagos }\end{array}$ & 69725 & 52.4 & 97.1 & 510 & 69.6 \\
\hline Guadalajara & 1460148 & 46.5 & 96.2 & 8223 & 79.4 \\
\hline $\begin{array}{l}\text { La Manzanilla } \\
\text { de la Paz }\end{array}$ & 3688 & 49.2 & 96.7 & 18 & 97.5 \\
\hline Jocotepec & 46521 & 43.3 & 96.3 & 198 & 98.0 \\
\hline Mascota & 14477 & 42.4 & 98.6 & 58 & 104.4 \\
\hline $\begin{array}{c}\text { Atemajac de } \\
\text { Brizuela }\end{array}$ & 6717 & 40.2 & 97.6 & 23 & 114.6 \\
\hline $\begin{array}{c}\text { Cabo } \\
\text { Corrientes }\end{array}$ & 10303 & 43.5 & 97.6 & 38 & 115.1 \\
\hline Atenguillo & 3899 & 42 & 95.4 & 13 & 120.2 \\
\hline Villa Hidalgo & 20257 & 33 & 94.4 & 50 & 126.2 \\
\hline $\begin{array}{l}\text { Ahualulco de } \\
\text { Mercado }\end{array}$ & 23362 & 31.9 & 98.7 & 58 & 126.8 \\
\hline Unión de Tula & 13446 & 53.2 & 98.5 & 40 & 176.1 \\
\hline $\begin{array}{c}\text { Santa María } \\
\text { del Oro }\end{array}$ & 2028 & 46.4 & 95.7 & 5 & 180.1 \\
\hline Huejúcar & 5633 & 38.2 & 87.9 & 10 & 189.1 \\
\hline Etzatlán & 19847 & 39.3 & 94.4 & 38 & 193.8 \\
\hline
\end{tabular}

Fuente: Estimaciones propias con base en datos del INEGI (2014, 2015 y 2020). 


\subsection{Vulnerabilidad 3: carga de localización}

El concepto Carga de localización propuesto hace referencia a los factores adversos que enfrenta el empleo turístico y los trabajadores del sector, manifestados en costos de hacer negocios y la masificación de la convivencia, en el ámbito de vida cotidiana y en los medios de transporte usados. Otra manera de entender este concepto es verlo como el reverso de la noción básica y muy conocida en economía urbana denominada "ventajas de localización" (Egan y Nield, 2000), ya que una buena ubicación se convierte en carga cuando hay una crisis. Para medir este indicador, se consideraron tres referentes sobre la relación entre dinamismo del sector turismo, condiciones de vida y vulnerabilidad de localización:

a) El porcentaje de viviendas habitadas arrendadas. Valor aproximado para incorporar la renta del suelo como una carga a enfrentar durante la pandemia y posterior a ella. A mayor demanda turística y dinamismo económico, tanto establecimientos como habitantes enfrentan rentas más elevadas. En Jalisco se observa que los municipios dinámicos tienen porcentajes altos, mientras los pequeños pueblos de las regiones rurales tienen bajos porcentajes.

b) La distancia del centro del municipio al aeropuerto internacional jalisciense más cercano. Este indicador es una medida aproximada para hacer referencia a la dependencia del turismo basado en uso de transporte masivo, que arriba desde grandes distancias.

c) Empleo total del subsector 721 referente a establecimientos de alojamiento temporal. Este es un indicador del peso del consumo final de servicios por parte de los visitantes a un destino.

El índice por carga de localización está formulado de la siguiente manera:

$$
V C L=\left(\left(\left(P^{*}(V R / 100)\right) /(E 72 / E A T) *(1 / D T A)\right) * V R\right.
$$

En donde:

$\mathrm{VCL}=$ Vulnerabilidad por carga de localización.

$\mathrm{P}=$ Población total del municipio 2015.

VR = Porcentaje de viviendas particulares habitadas alquiladas.

E72 = Total de personal ocupado en alojamiento temporal y alimentos (sector 72).

DTA $=$ Distancia al aeropuerto internacional más cercano en Jalisco.

EAT $=$ Total de empleados en establecimientos de alojamiento (subsector 721). 
En este caso se decidió introducir el indicador VR como multiplicador al final de la fórmula, para darle más peso a la dificultad de pagar alquiler como un problema que conduce al cierre de empresas, lo cual se incrementa por los impactos inmediatos del COVID-19. En la tabla 3 presenta los resultados de este indicador.

En este caso, las economías locales más vulnerables son las metropolitanas, con Puerto Vallarta a la cabeza, seguido de seis municipios de la zona metropolitana de Guadalajara y tres ciudades medias, una de las cuales (Chapala) es también uno de los lugares con más turismo y retirados extranjeros en el estado de Jalisco. Además de estos lugares, destacan en la tabla de los 25 municipios más vulnerables, centros turísticos como Tequila, San Juan de los Lagos, Talpa de Allende, Cihuatlán y la Huerta.

\subsection{Análisis integrado de vulnerabilidad}

La figura 2 muestra que, como se esperaba, el municipio de Puerto Vallarta es el que combina la mayor vulnerabilidad en las tres dimensiones, seguido del municipio de Guadalajara. Existen otros municipios con vulnerabilidades muy altas en por lo menos dos de las dimensiones, entre los que se encuentran La Huerta y Mazamitla

Con el propósito de identificar mejor los retos que representa el COVID-19 para el turismo en Jalisco, enseguida se presenta la relación entre los indicadores de vulnerabilidad y la incidencia relativa del COVID-19, tomando en cuenta la población municipal (un indicador que mide cantidad de habitantes por caso de contagio confirmado, según el dato acumulado al 6 de julio de 2020).

En la gráfica 2 muestra que Puerto Vallarta sobresale con el más alto índice de vulnerabilidad y una de las mayores tasas de contagio; mientras, en el extremo opuesto, se encuentra Tapalpa que registró un bajo índice de vulnerabilidad y una tasa baja de contagio (un contagiado por cada 19 mil 506 personas). Estas diferencias en la relación vulnerabilidad-incidencia del COVID-19, plantean retos de política que varían por tipo de municipios, según se muestra en la sección siguiente. 
Tabla 3. Vulnerabilidad por carga de localización de los municipios turísticos de Jalisco

\begin{tabular}{|c|c|c|c|c|c|c|c|}
\hline Municipio & $\begin{array}{c}\text { Población } \\
\text { total } \\
(2015)\end{array}$ & $\begin{array}{c}\text { Total de } \\
\text { viviendas } \\
\text { habitadas }\end{array}$ & $\begin{array}{l}\text { Porcentaje } \\
\text { de } \\
\text { viviendas } \\
\text { alquiladas } \\
\text { (2015) }\end{array}$ & $\begin{array}{c}\text { Personal } \\
\text { ocupado } \\
\text { alojamiento } \\
\text { y alimentos } \\
\text { (2014) }\end{array}$ & $\begin{array}{c}\text { Empleados } \\
\text { en } \\
\text { alojamiento }\end{array}$ & $\begin{array}{c}\text { Distancia }(\mathrm{km}) \\
\text { a aeropuerto } \\
\text { internacional } \\
\text { de Jalisco }\end{array}$ & $\begin{array}{l}\text { Vulnerabilidad } \\
\text { por carga de } \\
\text { localización }\end{array}$ \\
\hline $\begin{array}{l}\text { Puerto } \\
\text { Vallarta }\end{array}$ & 275640 & 79622 & 31.7 & 20318 & 9393 & 5.1 & 792054.7 \\
\hline Guadalajara & 1460148 & 393530 & 33 & 47334 & 8223 & 18.3 & 457421.8 \\
\hline $\begin{array}{c}\text { San Pedro } \\
\text { Tlaquepaque }\end{array}$ & 664193 & 166239 & 25.6 & 7658 & 950 & 13.9 & 151749.7 \\
\hline Zapopan & 1332272 & 358742 & 31 & 26268 & 2415 & 30.4 & 124902.5 \\
\hline Tonalá & 536111 & 129922 & 27.5 & 4377 & 203 & 23.5 & 29096.4 \\
\hline El Salto & 183437 & 44921 & 22 & 1640 & 100 & 15.8 & 15574.3 \\
\hline $\begin{array}{l}\text { Tlajomulco } \\
\text { de Zúñiga }\end{array}$ & 549442 & 145220 & 27.1 & 5540 & 208 & 36.4 & 15358.3 \\
\hline Chapala & 50738 & 13597 & 25.6 & 1694 & 383 & 32.8 & 8953.3 \\
\hline $\begin{array}{l}\text { Tepatitlán } \\
\text { de Morelos }\end{array}$ & 141322 & 36152 & 37.6 & 2143 & 185 & 79.8 & 5748.3 \\
\hline Ocotlán & 99461 & 25826 & 27.8 & 1436 & 150 & 66.1 & 4369.5 \\
\hline $\begin{array}{c}\text { San Juan } \\
\text { de los Lagos }\end{array}$ & 69725 & 16909 & 27.7 & 1586 & 510 & 143.1 & 4340.0 \\
\hline Tequila & 42009 & 9956 & 25.5 & 952 & 300 & 81.9 & 4121.7 \\
\hline Jocotepec & 46521 & 10554 & 18.6 & 787 & 198 & 55.3 & 3936.6 \\
\hline Zapotlanejo & 68519 & 17671 & 26.7 & 960 & 45 & 31.8 & 2696.7 \\
\hline Villa Corona & 17824 & 4683 & 17.7 & 396 & 218 & 68 & 2554.0 \\
\hline $\begin{array}{l}\text { Lagos de } \\
\text { Moreno }\end{array}$ & 164981 & 40658 & 20.5 & 1967 & 250 & 187.2 & 2296.2 \\
\hline Cihuatlán & 41300 & 11478 & 25.1 & 1733 & 888 & 245.2 & 2166.3 \\
\hline $\begin{array}{l}\text { Ixtlahuacán } \\
\text { de los } \\
\text { Membrillos }\end{array}$ & 53045 & 14363 & 22.7 & 231 & 10 & 24.1 & 2162.9 \\
\hline Sayula & 36778 & 9243 & 27 & 474 & 83 & 129.5 & 1342.7 \\
\hline La Barca & 65055 & 16246 & 16.3 & 734 & 90 & 102.8 & 1264.8 \\
\hline $\begin{array}{l}\text { Zapotlán } \\
\text { el Grande }\end{array}$ & 105423 & 27948 & 27.7 & 1991 & 120 & 144.2 & 1220.5 \\
\hline $\begin{array}{c}\text { Talpa } \\
\text { de Allende }\end{array}$ & 15126 & 4063 & 17.9 & 352 & 188 & 125.7 & 1150.4 \\
\hline La Huerta & 24563 & 7063 & 14.7 & 1121 & 895 & 263.5 & 1094.0 \\
\hline $\begin{array}{l}\text { Atotonilco } \\
\text { el Alto }\end{array}$ & 60480 & 15994 & 24.9 & 632 & 38 & 96.2 & 941.2 \\
\hline Acatic & 21530 & 5728 & 27.7 & 207 & 18 & 60.4 & 858.6 \\
\hline
\end{tabular}

Fuente: Estimaciones propias con base en datos del INEGI (2014, 2015 y 2020). 
Figura 2. Ubicación de municipios turísticos en una escala tridimensional de vulnerabilidad ante el COVID-19

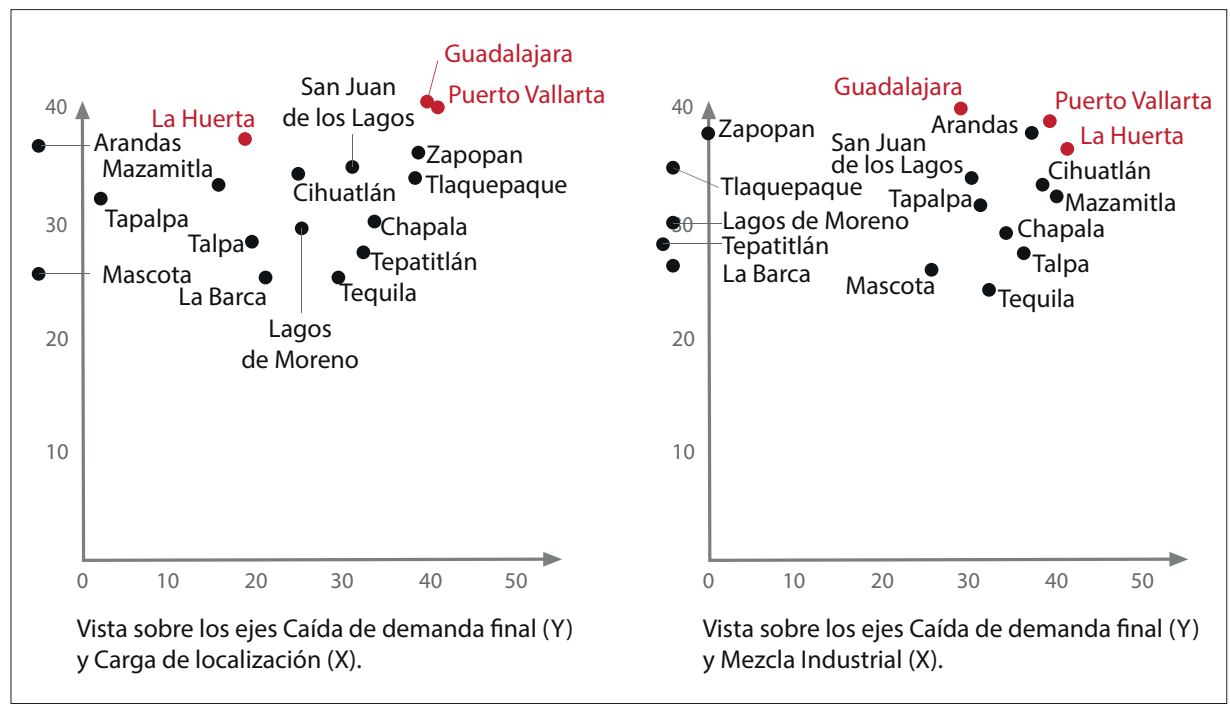

Fuente: Elaboración propia.

Gráfica 2. Índice de vulnerabilidad e incidencia de contagio por municipio

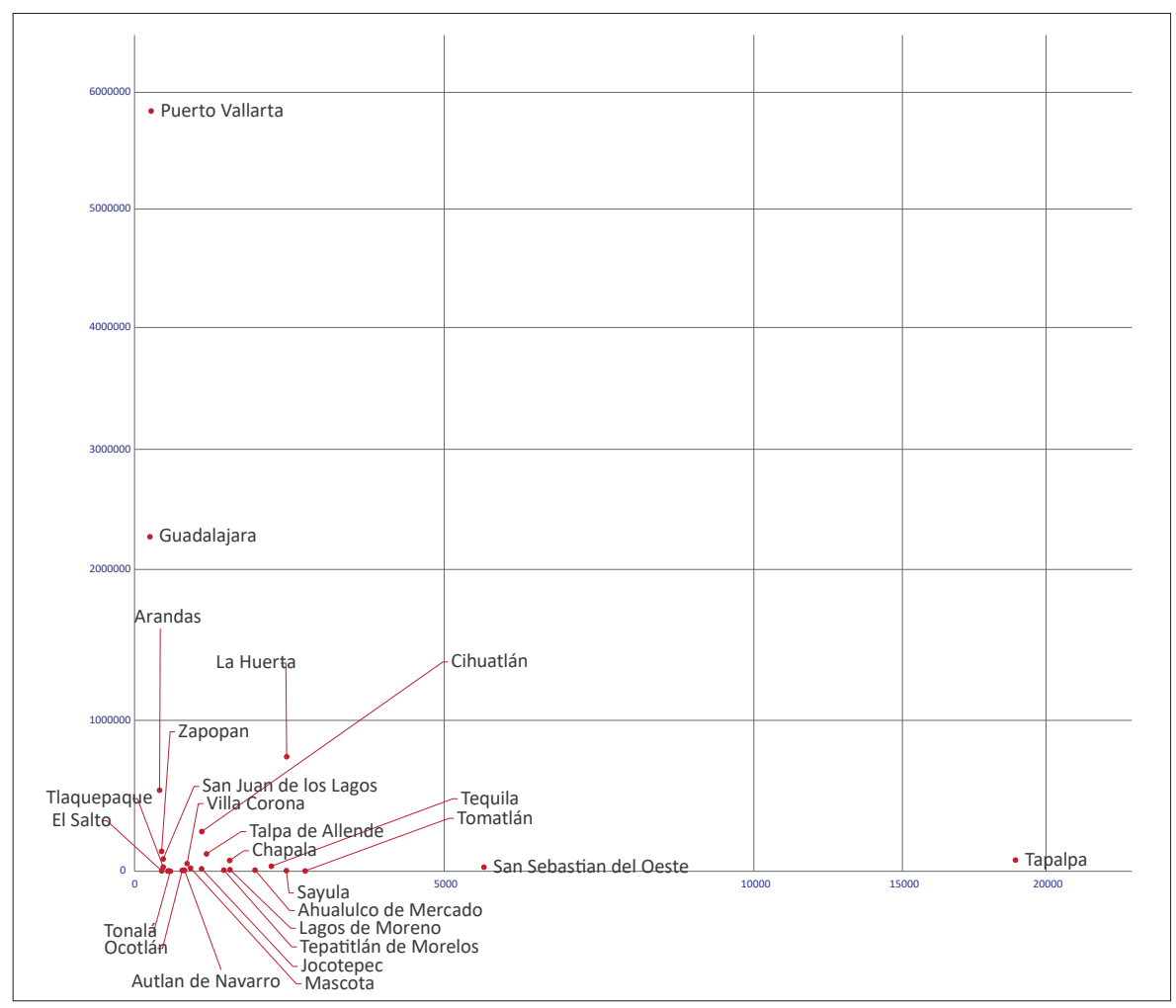

Fuente: Elaboración propia con base en datos de la Secretaría de Salud de Jalisco (SSJ) y boletines diarios de prensa, 28 de marzo a 6 de julio de 2020. 


\section{Una tipología de municipios turísticos jaliscienses y tendencias de contagio}

Dada la distribución del turismo, la vulnerabilidad y los indicadores de contagio registrados, vale la pena contextualizar las políticas de respuesta según tipo de municipios.

\subsection{Municipios turísticos metropolitanos}

Las áreas metropolitanas en Guadalajara, Puerto Vallarta y, en menor medida, Ocotlán, son los que registraron el mayor número de casos en los primeros cuatro meses. La curva de contagios registró una tendencia creciente a partir del punto bajo del 10 de mayo, fecha en que se registraron tres casos en la metrópoli y solo uno en Guadalajara (SSJ, 2020). Desde entonces se alcanzaron máximos crecientes los días 13, 17 y 23 de junio, hasta llegar a los 553 casos en la zona, el día 6 de julio (ver gráfica 3).

El crecimiento de contagios se aceleró aún más en varios municipios metropolitanos a partir del 21 de junio, con Guadalajara invariablemente registrando más casos que los demás municipios, pero con una expansión capaz de generar una proliferación importante de la enfermedad, debido al uso del transporte colectivo y el regreso de algunas actividades (gráfica 4). Los mecanismos de exclusión, descuido de imagen y servicios urbanos en la parte con mayor población y carencia de infraestructura son muy similares.

Para el 6 de julio, el grupo de diez municipios metropolitanos de Guadalajara más Puerto Vallarta habían registrado un total de 13 mil 687 casos que representaban el $86.97 \%$ de registrados en Jalisco. Los cinco municipios con más casos acumulados eran: Guadalajara, Zapopan, Tlaquepaque, Puerto Vallarta y Tlajomulco, en ese orden (gráfica 5). 
Gráfica 3. Total de nuevos casos de COVID-19 en la zona metropolitana de Guadalajara y el municipio de Guadalajara

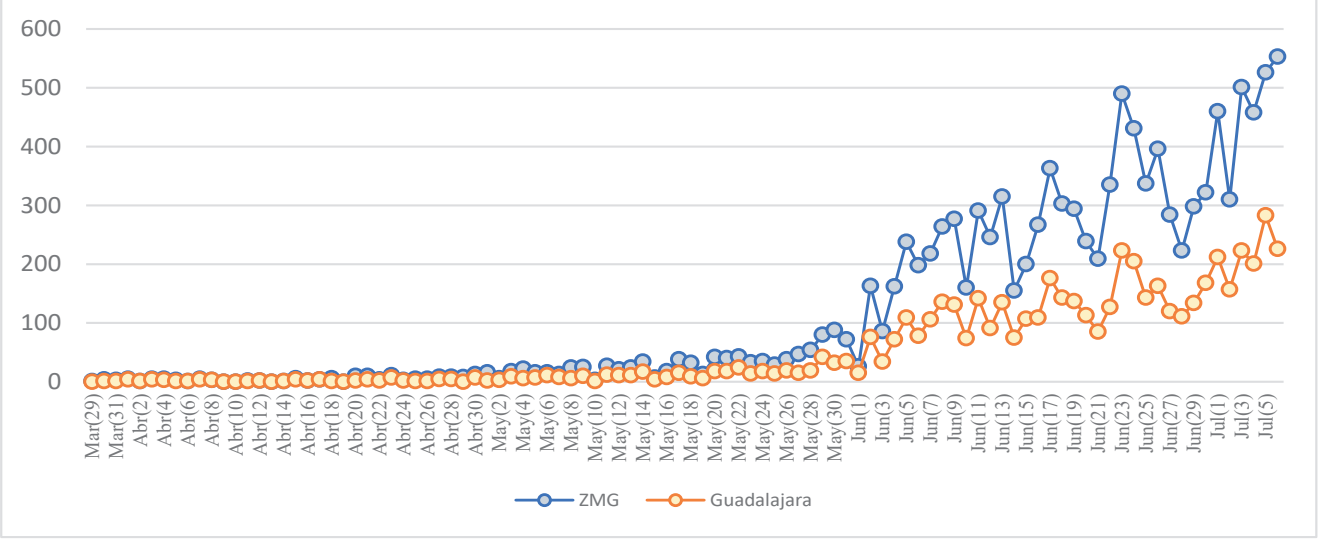

Fuente: Elaboración propia con base en datos de la SSJ y boletines diarios de prensa, 28 de marzo a 6 de julio de 2020.

Al respecto, es necesario considerar que tanto Puerto Vallarta como la zona metropolitana de Guadalajara han desarrollado una geografía de los servicios de hospedaje y turísticos muy segregada en lo general. Dicha distribución permite identificar nodos y corredores que presentan necesidades específicas a fin de incrementar su resiliencia en situaciones como la provocada por la pandemia del COVID-19.

En el caso de Guadalajara, se pueden distinguir diez polígonos que demandan formas de intervención específicas. En este municipio, es clave la combinación de apoyos a empresas y trabajadores, con acciones de política urbana dirigidas a reposicionar mejor los establecimientos de alojamiento dentro de los tejidos urbanos que los contienen. Guadalajara necesita acciones en seguridad, transporte, mejoramiento de imagen urbana y cambios en las políticas de uso del suelo. Destacan, en este sentido, las necesidades de los polígonos 1, 5, 6 y 10, que contienen los hoteles, establecimientos de alimentos y otro tipo de negocios turísticos que resultaron más afectados por la construcción de la línea 3 del tren ligero o aquellos lugares que enfrentan muy altas rentas de suelo (figura 3 ). 


\section{Gráfica 4. Municipios metropolitanos de Jalisco con más casos de COVID-19 diarios}

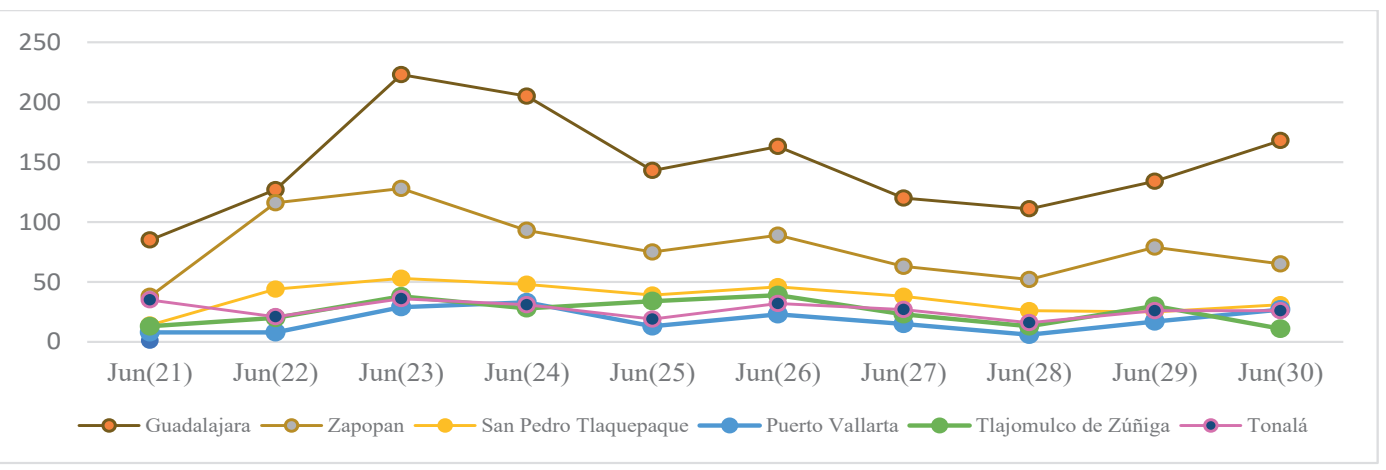

Fuente: Elaboración propia con base en datos de la SSJ y boletines diarios de prensa, 28 de marzo a 6 de julio de 2020.

Gráfica 5. Total de casos de COVID-19 en las zonas metropolitanas de Guadalajara y Puerto Vallarta (acumulados al 6 de julio de 2020)

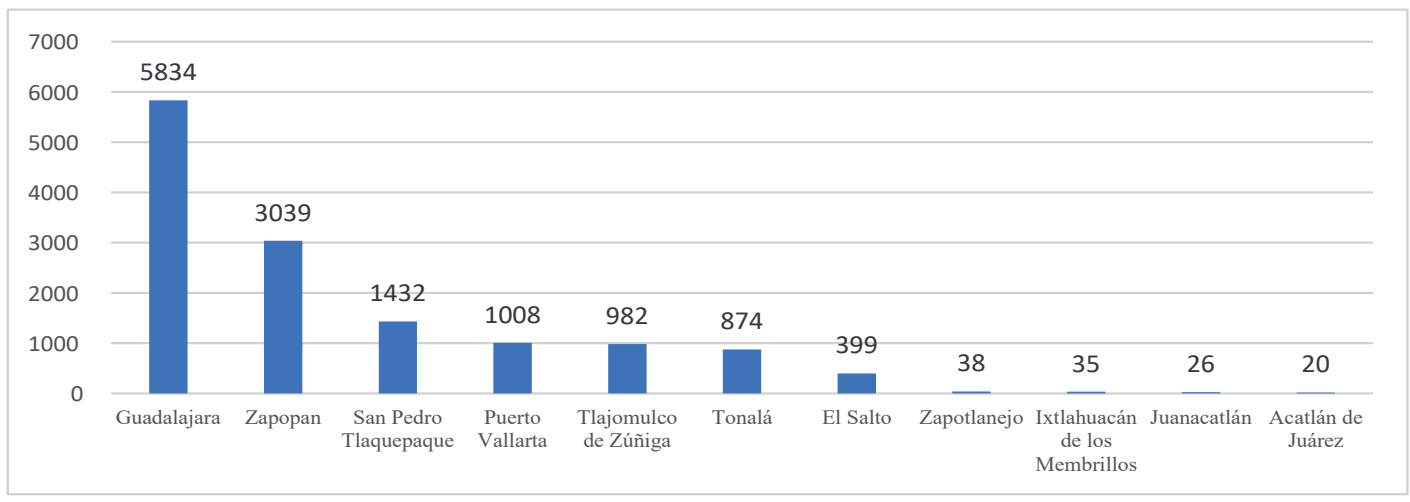

Fuente: Elaboración propia con base en datos de la SSJ y boletines diarios de prensa, 28 de marzo a 6 de julio de 2020.

En el caso de Puerto Vallarta, la pandemia ha incrementado la vulnerabilidad del modelo de "dos ciudades" que definió un corredor costero con la oferta de hospedaje y una zona urbana en las colinas donde habita la clase trabajadora. Además de las secuelas de la desigualdad urbana preexistentes, este modelo de ciudad magnifica las consecuencias de la política de distanciamiento social para hacer frente a la pandemia, y deja condiciones muy difíciles de enfrentar en el mediano y largo plazos para lograr integración social. 
Figura 3. Polígonos de oferta de servicios de alojamiento en la zona metropolitana de Guadalajara

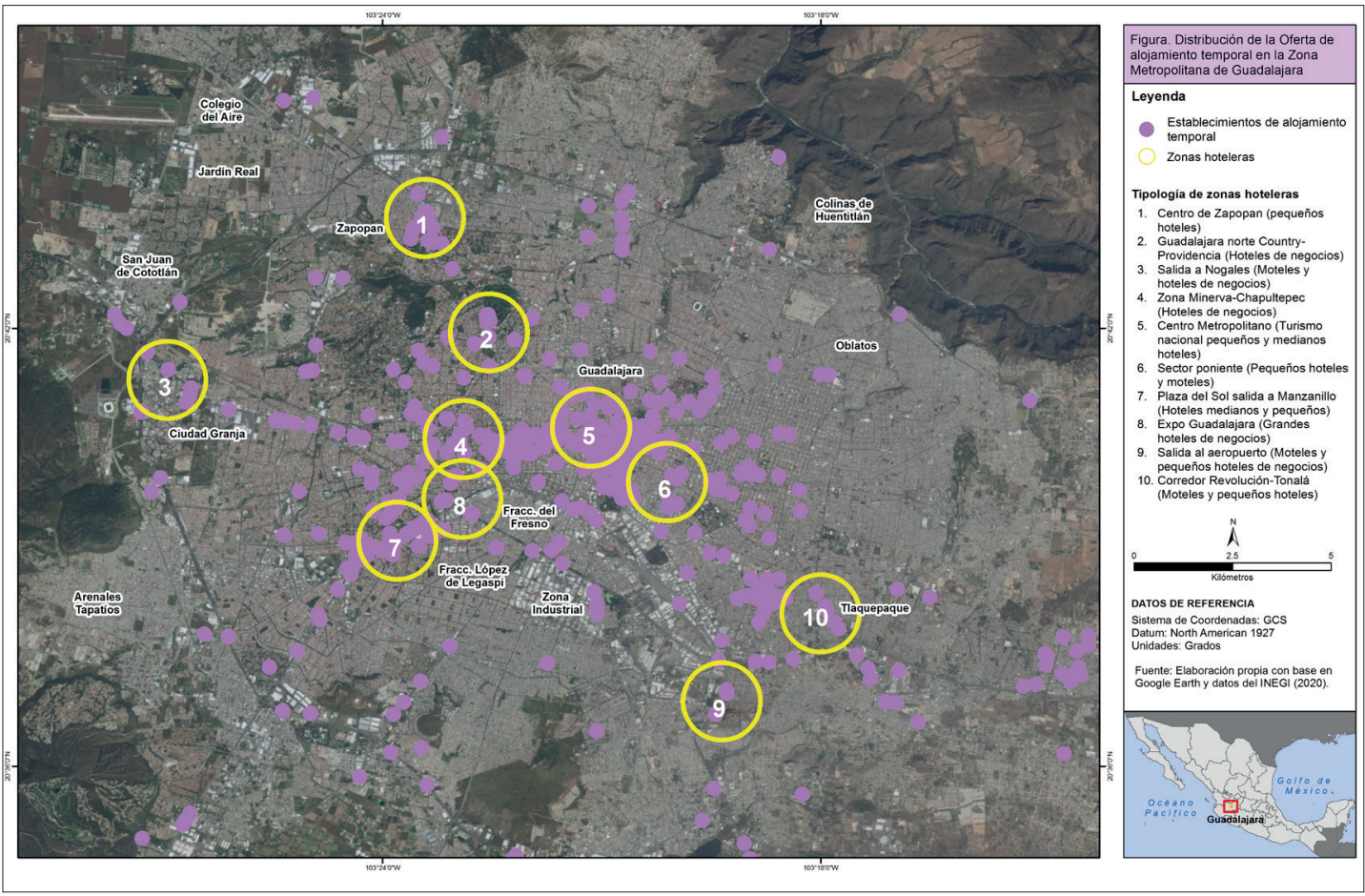

Fuente: Ver interior Figura 3.

En Puerto Vallarta se distingue una diversidad de polígonos, en donde se puede procurar el fortalecimiento de distritos que destaquen como áreas de oportunidad en el mediano y largo plazos, atendiendo a: i) la diversificación social y mejoramiento de accesibilidad desde los barrios de la ciudad; ii) soluciones urbanísticas de relevancia local e incluso internacional, como la reconversión de la unidad deportiva y el terreno baldío al sur del Hotel Sheraton como un complejo de servicios recreativo para la población y los visitantes; y iii) el mejoramiento del sistema de transporte hacia las áreas donde viven los trabajadores.

\subsection{Turismo rural en municipios costeros}

La pandemia del COVID-19 inició temprano en el grupo de cuatro municipios costeros de Jalisco que ofrecen turismo rural, pues Tomatlán tenía ya dos casos cuando comenzó el conteo por municipios, el 28 de marzo. El 17 de abril ese municipio registró un caso más. En los otros tres, los primeros casos se registraron el 13 de mayo en Cihuatlán, el 1 de junio en La Huerta, y el 12 de junio en Cabo Corrientes (El Tuito). A partir de entonces, la tendencia de contagios diarios de este grupo empezó 
a ser dominada por el municipio de Cihuatlán, que tuvo picos de cinco, seis y cinco casos diarios los días 17, 21 y 29 de junio, respectivamente (gráfica 6).

De esta manera, para el 6 de julio de 2020 se tenían registrados un total de 69 casos de contagios de COVID-19 confirmados. La distribución porcentual entre este grupo revela una gran diferencia en el cuidado que se tuvo al interior de los municipios e influencia del contexto regional y su exposición al turismo. Más de la mitad de estos casos (38), se habían registrado en Cihuatlán, un municipio cercano a ManzaniIlo, Colima, pero con una fuerte vocación agrícola. Mientras tanto, Cabo Corrientes, a pesar de su vecindad con Puerto Vallarta, uno de los principales sitios de contagio en Jalisco, tenía solamente ocho casos.

Dada la importancia de los servicios turísticos en el sustento de las comunidades rurales de la costa de Jalisco, estos destinos necesitan formas de apoyo especialmente diseñadas para estas condiciones.

Gráfica 6. Casos diarios de COVID-19 en los municipios costeros de Jalisco con turismo rural

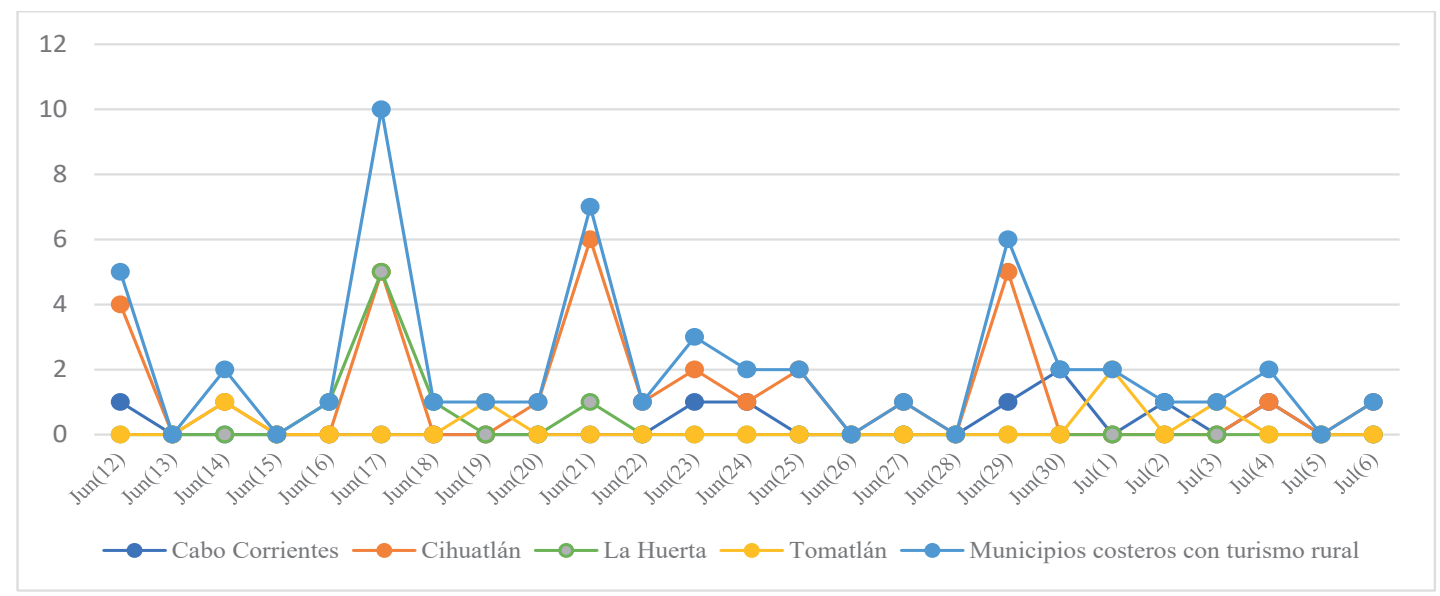

Fuente: Elaboración propia con base en datos de la SSJ y boletines diarios de prensa, 28 de marzo a 6 de julio de 2020.

El municipio de La Huerta, donde se ubican varias de estas comunidades, es uno de los más vulnerables a los efectos del COVID-19. En este municipio se encuentran poblaciones que dependen totalmente del turismo, personas que prácticamente han abandonado la producción de alimentos como opción de vida, y serios problemas de accesibilidad a vivienda o a empleos alternativos. En las pequeñas comunidades costeras, el turismo ha desarrollado un patrón de localización de establecimientos turísticos en las zonas centrales, porque tienen una mayor posibilidad de pagar los 
precios y alquiler del suelo de dichas zonas. Debido a este patrón de localización y otras causas diversas, estas localidades no cuentan con una infraestructura adecuada. En ellas, la imagen y los servicios pueden ser mejorados sustancialmente mediante obras de empleo temporal.

\subsection{Municipios de la ribera de Chapala}

En los polígonos turísticos de este corredor, los contagios de COVID-19 han tenido un comportamiento más homogéneo y un tanto tardío. Apenas el primero de junio los cuatro municipios contabilizaron por lo menos un caso. En este grupo, se registró una tendencia que alcanzó el máximo valor el 21 de junio (18 casos); no obstante, a partir de ahí, la tendencia fue decreciente en el periodo estudiado.

Como se observa en la gráfica7, Ocotlán, que es centro de una zona metropolitana regional, es el municipio que impulsa el comportamiento del grupo al registrar más casos diarios promedio. Para el 6 de julio, en estos cuatro municipios, se había registrado un total de 216 casos de los cuales el 60 por ciento correspondían a Ocotlán. En cambio, los municipios de Chapala y Jocotepec, con más oferta turística, tenían registrados 33 y 43 casos, respectivamente.

Gráfica 7. Casos diarios de COVID-19 en los municipios turísticos de la ribera de Chapala, Jalisco

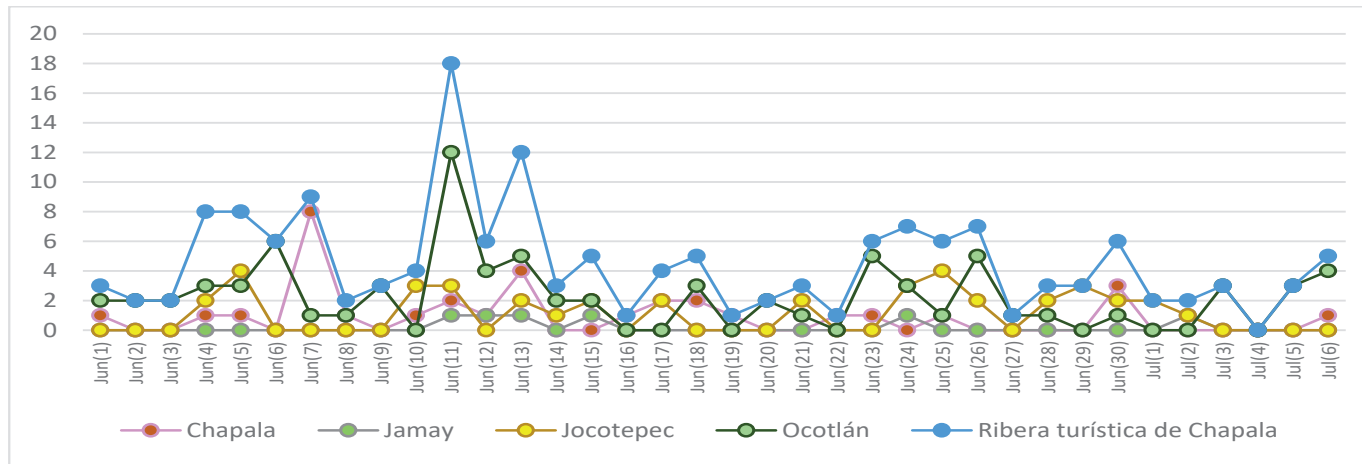

Fuente: Elaboración propia con base en datos de la SSJ y boletines diarios de prensa, 28 de marzo a 6 de julio de 2020.

Estos municipios presentan una imagen más madura en cuanto a consolidación urbana y desigualdad social, de lo que se presenta en las comunidades costeras de los municipios de Cihuatlán, La Huerta, Tomatlán y Cabo Corrientes, pero el funcionamiento de la relación servicios de hospedaje-asentamiento sede, es muy similar. Con excepción del corredor Ocotlán-Jamay, el resto de la ribera de Chapala mantiene un patrón de ocupación de uso de suelo que puede ofrecer múltiples opciones 
de mejora, mediante programas de apoyo dirigidos a crear empleo temporal y a renovar la oferta de servicios en el mediano y largo plazos.

\subsection{Pueblos mágicos}

Dada su localización, el tipo de oferta turística y de servicios de salud con que cuentan, su contexto regional y los accesos carreteros, los pueblos mágicos de Jalisco tienen grandes diferencias, registrando un patrón de contagios muy heterogéneo. Para el 20 de mayo, cinco de ocho municipios habían registrado por lo menos un caso. Entre esa fecha y el 6 de julio, la tendencia de registros diarios mostrada por este grupo estuvo dominada por Tlaquepaque, pues, al ser un municipio de la zona metropolitana de Guadalajara, asumió el patrón de contagios de esa ciudad (gráfica 8).

Gráfica 8. Casos diarios de COVID-19 en los pueblos mágicos de Jalisco

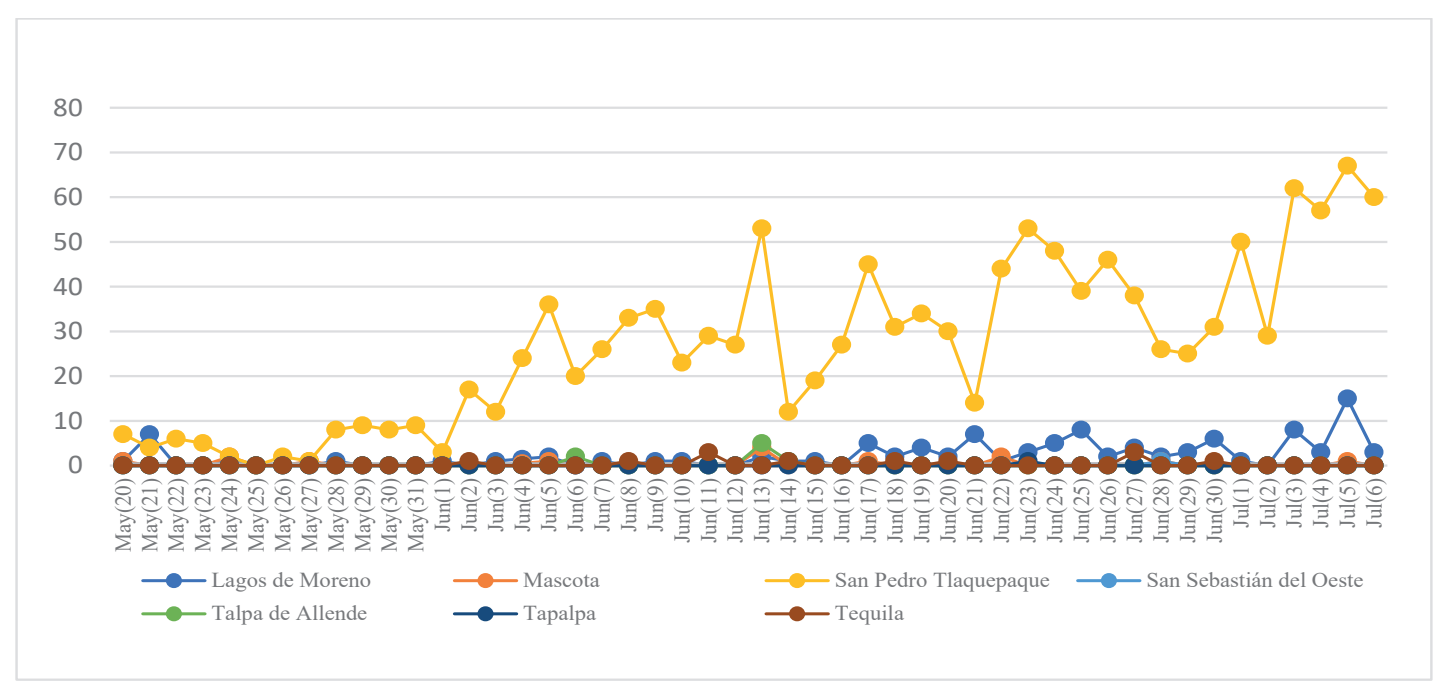

Nota: En esta gráfica no se incluye Mazamitla, por no presentar casos.

Fuente: Elaboración propia con base en datos de la SSJ.

y boletines diarios de prensa, 28 de marzo a 6 de julio de 2020 .

En el grupo de pueblos mágicos, los municipios de montaña muestran diferentes condiciones para reorientar la construcción de una base turística resiliente. De acuerdo con los datos de contagio de la SSJ, hasta el 6 de julio de 2020 el grupo de ocho pueblos mágicos había registrado un total de mil 590 casos, de los cuales el 90\% (mil 433) se encontraban en San Pedro Tlaquepaque, y el otro 7\% se había registrado en Lagos de Moreno (107 casos), que es en realidad una de las principales ciudades medias de Jalisco con base industrial. Los municipios de montaña seguían 
siendo lugares con muy baja incidencia. Mazamitla no tenía todavía ningún caso, mientras que Tapalpa y San Sebastián del Oeste tenían registrado solo un caso en cada lugar.

La falta de información oportuna, la carencia de servicios de salud de primer nivel y una escasa coordinación entre prestadores de servicio, población local y gobierno impiden ese escenario. Esas necesidades seguirán en el futuro próximo, por lo que son indicios del tipo de acciones necesarias en pueblos de montaña, en donde los establecimientos de servicios tienen ubicaciones centrales en los cascos urbanos. Estos pueblos también presentan diferencias; por ejemplo, en comparación con el municipio de Mazamitla, el de Tapalpa tiene una menor vulnerabilidad y más oportunidades de desarrollar un sector de producción de alimentos para satisfacer demandas locales.

\subsection{Destinos especializados en turismo religioso}

Los principales centros de turismo religioso en Jalisco son Talpa de Allende y San Juan de los Lagos. Para el 6 de julio de 2020, estos dos municipios acumulaban un total de 163 casos. Talpa de Allende tuvo pocos casos, por lo que la dinámica de este grupo es impulsada por San Juan de los Lagos, que tenía el 98\% del grupo (150 casos). En la dinámica diaria durante el periodo de mayor auge, San Juan de los Lagos tuvo un ciclo de rápido crecimiento entre el 30 de mayo y el 6 de junio al registrar 15 casos, aunque de ahí devino en tendencia descendente (gráfica 9). Por su parte, Talpa de Allende registró, el 13 de junio, la cifra récord de cinco casos, que son bastantes si se considera que este es un pueblo comparativamente pequeño, con 15 mil 126 pobladores.

En ambos sitios, la localización de los establecimientos de turismo tiende a ubicarse en la zona central, en los alrededores de los templos principales. Esta situación propicia que dichas aglomeraciones sean el epicentro de la crisis económica local. Si se toma como referencia el cierre de sitios de trabajo en estos lugares, el efecto expansivo abarca las colonias populares. Esto demanda el diseño de acciones para cada uno de estos polígonos y sus zonas de influencia, así como revisar, en el mediano y largo plazos, de qué manera la organización espacial de los servicios contribuyó a magnificar los impactos del COVID-19 en San Juan de los Lagos, pero no tanto en Talpa de Allende. 
Gráfica 9. Casos diarios de COVID-19 en las localidades de turismo religioso de Jalisco

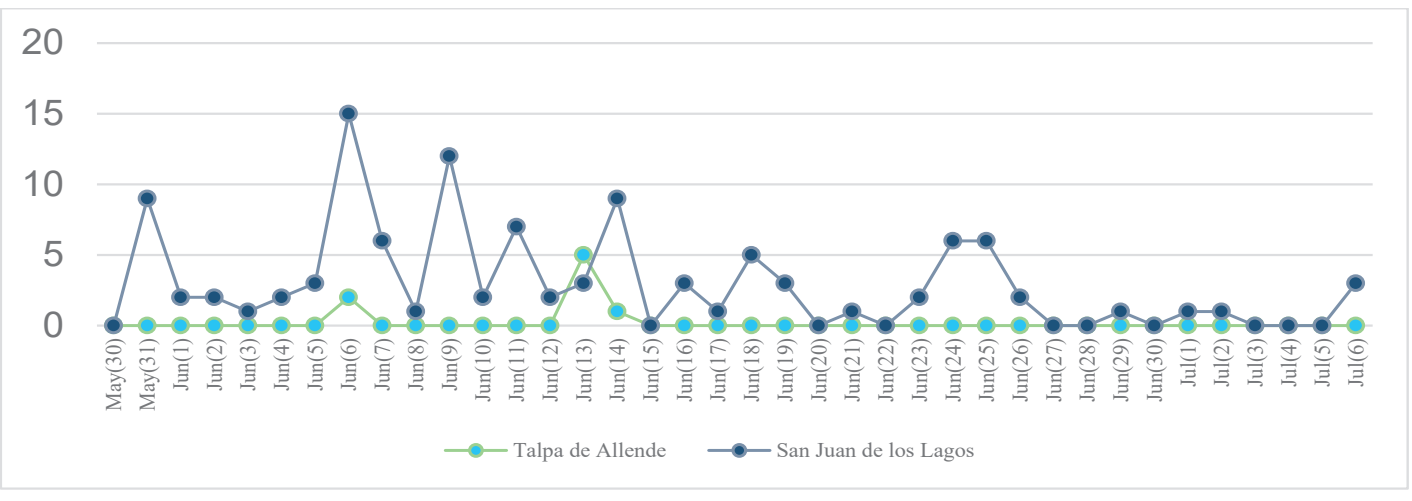

Fuente: Elaboración propia con base en datos de la SSJ y boletines diarios de prensa, 28 de marzo a 6 de julio de 2020.

\subsection{Ciudades medias}

Tres de las ciudades medias de Jalisco que ejemplifican los problemas en este grupo son Arandas, Ciudad Guzmán (en el municipio de Zapotlán el Grande) y Tepatitlán de Morelos, en Los Altos. En estos municipios los contagios del COVID-19 iniciaron el 24 de abril, cuando Tepatitlán registró su primer caso, pero Ciudad Guzmán y Arandas tuvieron su primer caso hasta el 10 y el 11 de mayo, respectivamente. Ciudad Guzmán (Zapotlán el Grande) ha impulsado la dinámica mostrada por este grupo con picos los días 9, 16 y 24 de junio y el 3 de julio, cuando registró 13, 18, nueve y ocho casos, respectivamente (gráfica 10).

Para el 6 de julio, estas ciudades habían acumulado un total de 307 casos, de los cuales el $62 \%$ se habían registrado en Ciudad Guzmán, mientras que Arandas solo tenía el $6 \%$ con 19 casos. Si bien en este tipo de ciudades la oferta de servicios de hospedaje, al igual que la de alimentos y bebidas, no tiene patrones de distribución tan concentrados como los observados en los tipos de destinos revisados hasta ahora, es claro que, en términos generales, tienden a ubicarse en las áreas centrales tradicionales.

Este tipo de oferta está mejor integrada a sus contextos urbanos, pero carece de las ventajas de economías de aglomeración. Las ciudades en cuestión no cuentan con el potencial de recuperarse rápidamente de la crisis generada por el COVID-19, pues carecen de atractivos relevantes. 
Gráfica 10. Casos diarios de COVID-19: municipios donde se localizan las ciudad medias de Jalisco

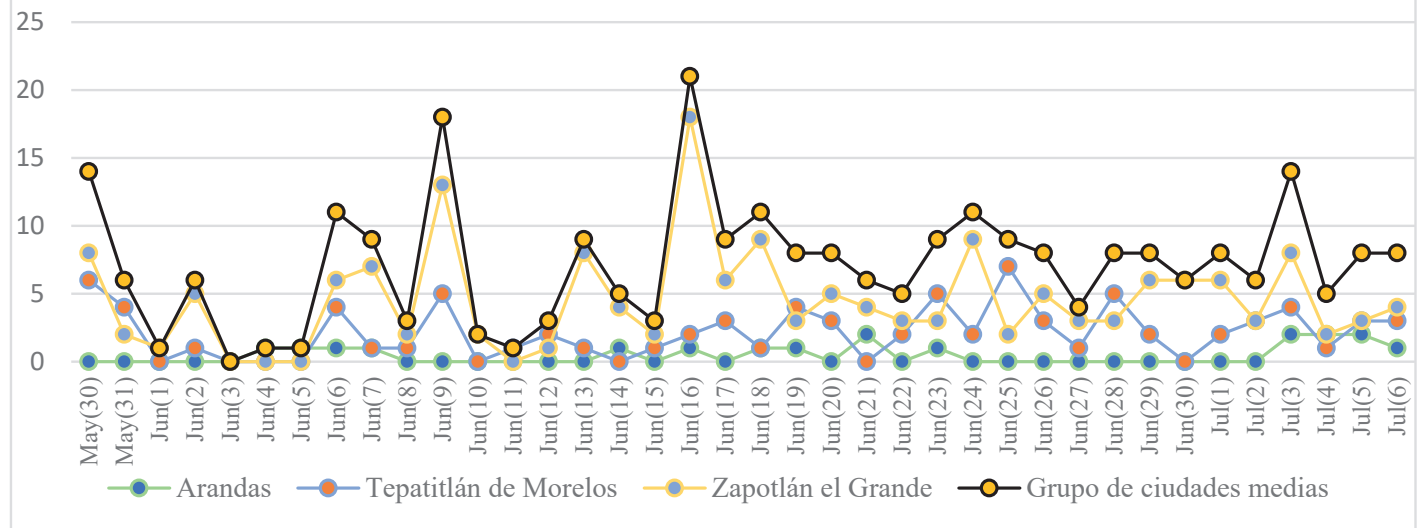

Fuente: Elaboración propia con base en datos de la SSJ y boletines diarios de prensa, 28 de marzo a 6 de julio de 2020.

Además de las acciones de mitigación de corto plazo, en estos lugares se necesitan eventos y productos para incentivar mayores niveles de ocupación. Lo anterior puede abarcar diversificación de la oferta de servicios turísticos, programas de capacitación para mejorar la oferta, la prestación de servicios y obras para mejorar la imagen urbana.

\section{Lineamientos de política en centros turísticos ante la pandemia COVID-19}

Enseguida, se identifican líneas de acción para un programa que reduzca la vulnerabilidad y los impactos, en dos etapas: la primera, dirigida a mitigar las manifestaciones más agudas del problema durante la política de distanciamiento social, y la segunda, orientada a cambiar radicalmente la organización industrial del sector. La distribución de infectados es un aspecto clave en el diseño de las políticas encaminadas a enfrentar la situación durante la etapa aguda de la pandemia, cuando más se necesita el distanciamiento social, así como la severidad del contagio y su localización por municipio son importantes.

En el caso de Jalisco la situación durante los primeros meses de la pandemia cambió con rapidez. Para el 26 de abril de 2020, aproximadamente 15 días antes de la fecha pronosticada a nivel nacional como la cresta de la ola de infecciones, había un grupo de 30 municipios con al menos un caso de infección. Para el 6 de julio, 
solo quedaban 19 de los 125 municipios de Jalisco sin registro de casos. Para esta fecha, lejos había quedado la historia del pequeño municipio de Cuautla, un lugar ubicado en un punto intermedio entre Guadalajara y Puerto Vallarta, en donde la llegada de inmigrantes infectados, procedentes del estado de Washington, provocó el contagio a varias personas (10 casos).

La geografía de la pandemia se había vuelto metropolitana: además de Puerto Vallarta, se habían consolidado como municipios con mayor afectación los municipios de Guadalajara, Tlaquepaque, Tonalá y El Salto (menos población por infectados), que comprueban la vulnerabilidad por localización.

Considerando los efectos de la pandemia del COVID-19 y las vulnerabilidades estudiadas, Jalisco necesita un plan integral por etapas, dirigido a cambiar la cara a los destinos turísticos y a lograr objetivos como: establecimientos con instalaciones más modernas, edificaciones menos consumidoras de energías fósiles y más autosuficientes, servicios integrados a cadenas de proveeduría local, mejores sistemas de manejo de residuos sólidos y un uso más eficiente de agua y suelo, trabajadores mejor calificados y mejor pagados, mejor oferta de transporte en las ciudades con unidades más eficientes en el consumo de energía y un uso más intensivo de tecnologías de información y comunicación.

Etapa 1. Resolver las manifestaciones inmediatas de la vulnerabilidad económica

Estas son medidas de corto plazo para mitigar los impactos más fuertes asociados a las distintas vulnerabilidades señaladas líneas arriba. Como se muestra en la tabla siguiente, se pueden distinguir dos tipos de medidas dirigidas a: a) mantener la oferta de empleo, y b) mantener los ingresos básicos familiares. 
Tabla 4. Tipología de soluciones y lineamientos según tipo de impactos a mitigar en el corto plazo

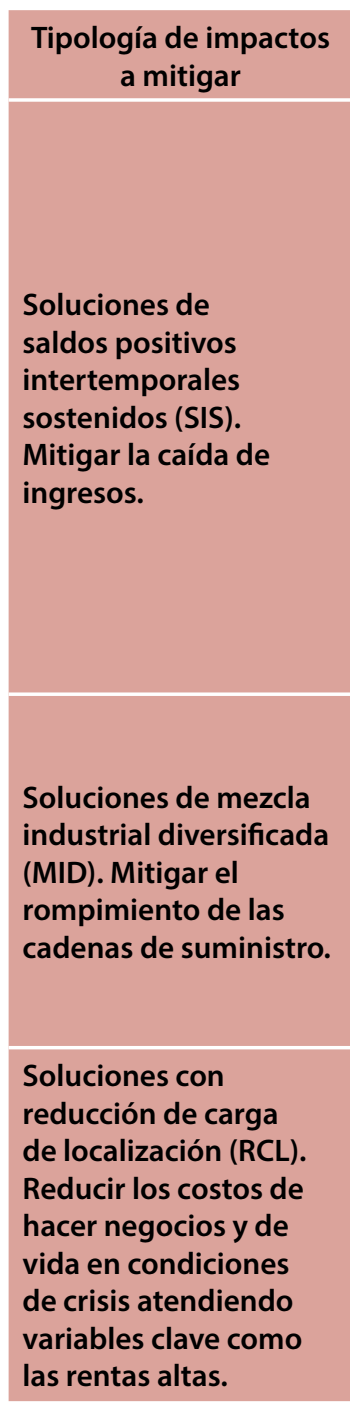

\section{Lineamientos dirigidos a mantener oferta de empleo.}

Preventa de paquetes "destino incluido".

Paquetes de arrendamiento subsidiado de establecimientos de hospedaje y alimentación para albergar y servir a prestadores de servicios de salud y/o pacientes con COVID-19.

Prórroga de pago de permisos, impuestos, cuotas y servicios públicos.

Reorientación del impuesto de hospedaje hacia un fondo de inversión para el desarrollo del destino turístico.

Foro intermunicipal de turismo y desarrollo con la participación tripartita (gobierno estatal, gobiernos de principales municipios turísticos y empresarios).

Apoyo directo especial a empresas por su ubicación en cadenas de servicio.

Prórroga de pago de permisos, impuestos, cuotas y servicios públicos.

Estímulo al desarrollo de proveedores locales y la sustitución de provisión de bienes y servicios.

Programa especial de reducción de impuesto por ingresos de arrendamiento de inmuebles.

Acuerdo municipal para la reducción consensada de rentas de locales comerciales y viviendas.

Relajar reglas de uso de suelo.

\section{Lineamientos dirigidos a mantener ingresos básicos de las familias}

Sueldos parciales garantizados por tipo de empleo.

Becas de capacitación para el trabajo.

Prórroga o reducción definitiva temporal de impuestos.

Reparto de despensas por tipo de familia.

Apoyo prioritario a empresas familiares que proveen servicios y bienes especializados a la economía local.

Contratación temporal de trabajadores para desarrollar actividades especializadas que ayuden a mantener la imagen y seguridad del destino turístico.

\section{Contratación de servicios de} mantenimiento de fincas $y$ establecimientos de servicios.

Programas integrales de mantenimiento urbano en zonas densamente pobladas con trabajadores locales.

Apoyo directo al pago de rentas.

Fuente: Elaboración propia.

\section{Etapa 2. Incrementar la resiliencia del destino en el mediano y largo plazos}

\section{Estas son medidas dirigidas a impulsar el desarrollo de la diversidad económica de los destinos turísticos e incrementar la resiliencia, incluso a nivel de barrio.}


Tabla 5. Tipología de soluciones y lineamientos, según tipo de impactos a mitigar

\begin{tabular}{|c|c|c|}
\hline $\begin{array}{l}\text { Tipología de } \\
\text { soluciones a } \\
\text { emprender }\end{array}$ & $\begin{array}{l}\text { Lineamientos dirigidos } \\
\text { a mantener oferta de empleo }\end{array}$ & $\begin{array}{l}\text { Lineamientos dirigidos a mantener } \\
\text { ingresos básicos de las familias }\end{array}$ \\
\hline $\begin{array}{l}\text { Soluciones de } \\
\text { saldos positivos } \\
\text { intertemporales } \\
\text { sostenidos (SIS) }\end{array}$ & $\begin{array}{l}\text { Impulsar el mercado doméstico y segmentos } \\
\text { especializados del mercado internacional. } \\
\text { Desarrollar un sistema alternativo de pago } \\
\text { de permisos, impuestos, cuotas y servicios } \\
\text { públicos. Formación de empresas con inversión } \\
\text { de portafolio que incluye servicios y bienes no } \\
\text { turísticos. } \\
\text { Programa de apoyo a la renovación integral a } \\
\text { establecimientos de hospedaje y alimentación. } \\
\text { Reorientación y rediseño del impuesto de } \\
\text { hospedaje hacia un fondo de inversión para el } \\
\text { desarrollo del destino turístico. } \\
\text { Formalizar la creación de una Agencia } \\
\text { intermunicipal de turismo y desarrollo resiliente } \\
\text { (AITDR). }\end{array}$ & $\begin{array}{l}\text { Mejoramiento de sueldos y crecimiento de } \\
\text { fondo de pensiones y contingencias. } \\
\text { Creación de un fideicomiso popular } \\
\text { municipal de pensiones y ahorro financiado } \\
\text { con multas. } \\
\text { Bancos de alimentos a costo reducido. } \\
\text { Empleo temporal en actividades de } \\
\text { remodelación de unidades con preferencia a } \\
\text { trabajadores locales. } \\
\text { Financiamiento de proyectos estratégicos } \\
\text { con un fondo especial administrado por la } \\
\text { AITDR. }\end{array}$ \\
\hline $\begin{array}{l}\text { Soluciones de } \\
\text { mezcla industrial } \\
\text { diversificada } \\
\text { (MID) }\end{array}$ & $\begin{array}{l}\text { Apoyo directo especial a formación de empresas } \\
\text { no turísticas que pueden prestar parte de sus } \\
\text { bienes y servicios a la cadena de servicio. } \\
\text { Prórroga de pago de permisos, impuestos, cuotas y } \\
\text { servicios públicos. } \\
\text { Cambios en la regulación de uso de suelo para } \\
\text { proponer distritos de uso mixto. } \\
\text { Programa integral de apoyo al desarrollo de } \\
\text { proveedores locales de bienes y servicios. }\end{array}$ & $\begin{array}{l}\text { Apoyo prioritario a empresas no turísticas } \\
\text { que proveen servicios y bienes especializados } \\
\text { a la economía local. } \\
\text { Programas de capacitación para el trabajo en } \\
\text { empresas no turísticas. }\end{array}$ \\
\hline $\begin{array}{l}\text { Soluciones } \\
\text { con reducción } \\
\text { de carga de } \\
\text { localización }(R C L)\end{array}$ & $\begin{array}{l}\text { Financiamiento a la adquisición de bienes } \\
\text { inmuebles (reducir el peso del arrendamiento en } \\
\text { la economía local). } \\
\text { Mejora de infraestructura y equipamiento para } \\
\text { facilitar el acceso a visitantes con menores riesgos } \\
\text { y costos derivados del uso de transporte masivo. } \\
\text { Regulación y monitoreo de la vivienda en renta. } \\
\text { Redistribución del gasto público y adopción de un } \\
\text { sistema progresivo de impuesto predial. }\end{array}$ & $\begin{array}{l}\text { Programa integral de mantenimiento de } \\
\text { fincas y establecimientos de servicios. } \\
\text { Programas integrales de mantenimiento } \\
\text { urbano en zonas densamente pobladas con } \\
\text { trabajadores locales. } \\
\text { Planeación integral de distritos urbanos } \\
\text { (imagen, uso de suelo, infraestructura). }\end{array}$ \\
\hline
\end{tabular}

\subsection{Criterios de aplicación}

En la adopción de medidas para enfrentar las consecuencias del COVID-19 en el sector turismo, es necesario buscar coherencia entre las acciones tomadas en sus primeras etapas y el objetivo a largo plazo de construir destinos resilientes y competitivos a nivel internacional. Los patrones de distribución socioespacial de la epi- 
demia y la geografía estatal del turismo permiten identificar tres criterios básicos, para guiar el diseño y la instrumentación de intervenciones públicas puntuales, y estrategias organizadas de los sectores empresarial y social, estos son:

\section{Criterio 1. Favorecer el funcionamiento de economías locales resilientes}

El objetivo central es crear una economía turística local resiliente. Tanto al diseñar apoyos a empresas o directos a población, es necesario considerar que la imagen y competitividad del destino turístico dependen de: a) un manejo integral de la imagen. No dejar caer ni un barrio; $b$ ) una estructura funcional de bienes y servicios. No dejar que desaparezca ningún servicio esencial para la competitividad; $y, c$ ) una fuerza de trabajo calificada. No dejar que emigre el personal calificado indispensable para el sector. A fin de lograr lo anterior, se necesita el uso intensivo de información sobre empresas, condiciones y contextos en los que operan.

\section{Criterio 2. Mejorar la integración de política económica y política urbana-regional}

Las medidas de distanciamiento social pusieron en evidencia las implicaciones de separar las políticas de desarrollo económico de las políticas urbanas y regionales. Para revertir ese proceso, son necesarias acciones que ayuden a inducir patrones de uso de suelo no favorecedores a monocultivos, terminar con la acumulación de terreno bajo el control de unas cuantas empresas o el abandono de la producción de bienes de consumo básico local para beneficiar productos de exportación. La seguridad alimentaria ha tomado una nueva dimensión en esta crisis, los centros turísticos de Jalisco pueden aprovecharla para empezar a desarrollar estrategias de abasto local.

La segregación socioespacial es un factor de riesgo preexistente, porque incrementa la exposición a riesgos de contagio, como el uso de transporte masivo, recorridos de grandes distancias, entre otras. Para reducir la vulnerabilidad también es necesario disminuir las incertidumbres y los costos del mercado de arrendamiento de inmuebles e impulsar modelos solidarios para solventar la situación; en el largo plazo, se necesitan bases de datos y mecanismos de regulación de este mercado.

\section{Criterio 3. Tomar en cuenta la localización urbana y regional de la oferta turística}

Los aspectos mencionados hasta ahora son relevantes; sin embargo, urge inducir cambios en los patrones de localización de la oferta de servicios turísticos y la producción de bienes y servicios complementarios, incluyendo la vivienda de los traba- 
jadores del sector. Algunos aspectos a considerar en la decisión de la distribución socio-territorial de acciones a emprender son: edad del establecimiento, como indicador de necesidad de remodelación integral; características de su planta laboral, incluyendo la distancia promedio y medios de transporte usado; vinculación con su entorno social urbano, indicador de su vulnerabilidad y su aportación a la formación de distritos de uso mixto; accesibilidad a principales nodos de origen de visitantes del establecimiento, considerando las diversas modalidades de transporte, distancia a establecimientos de salud y ubicación, con relación a las zonas de mayor contagio.

La distribución de la oferta es importante. Cada destino tiene una interacción diferenciada con sus regiones de influencia y su población local. Un criterio muy general en esta escala de análisis es el de fortalecer los vínculos regionales en la reconfiguración de las cadenas de suministro. A nivel urbano, tal distribución es el punto de partida para fortalecer la integración de este tipo de negocios con el tejido social y las aglomeraciones urbanas existentes. Sin dicha integración es casi imposible disminuir la desigualdad social intraurbana, la conformación de distritos urbanos de tipo mixto y un mayor énfasis a las formas de movilidad no motorizada que ayuden a reducir los riesgos de contagio.

\section{Conclusiones}

La pandemia del COVID-19 ha puesto a prueba la resiliencia de los destinos turísticos y las políticas de distanciamiento social han exhibido su vulnerabilidad. A principios de julio de 2020, en Jalisco se había consolidado una relación directa entre el contagio y el peso del turismo en la economía local. Los centros de mayor contagio se encontraban en los municipios metropolitanos que concentran la oferta de servicios turísticos: Puerto Vallarta, Guadalajara y Zapopan, además de San Juan de los Lagos. Sin embargo, en todos los municipios el sector turístico estaba en crisis.

Los resultados presentados sugieren que, al diseñar políticas para mejorar la resiliencia y disminuir la vulnerabilidad, no se debe perder de vista que esta última es un problema que afecta en forma desigual a distintas empresas y sectores de la población. La tipología de municipios presentada ayuda a identificar mejor las poblaciones objetivo con necesidades similares y a considerar las diferencias. Por ejemplo, en el caso de los pueblos mágicos, la inclusión de San Pedro Tlaquepaque 
en ese grupo es inadecuada, pues este municipio presenta una dinámica de contagio y necesidades propias de la metrópoli.

La naturaleza multidimensional de la vulnerabilidad demanda acciones públicas y privadas para atender la situación en el corto plazo, pero también mayor participación comprometida de empresarios y sociedad, dirigida a reconvertir los destinos turísticos y hacerlos más resilientes. La meta no puede ser volver a la normalidad anterior, sino surgir de la crisis con una agenda de auténtico cambio del modelo de negocios, tanto a nivel de empresa como a nivel de destino turístico.

La condición de emergencia lleva a los tomadores de decisiones a apagar algunos fuegos que amenazan a la sociedad, pero es importante no perder de vista que es necesario aprender de esa experiencia, y revisar las relaciones causales que hay detrás de la vulnerabilidad social presente en los destinos turísticos, ante este tipo de situaciones.

\section{Referencias}

Batista, F., Marín, M. A., Konštantín, R., Ribeiro, R., Freire, S. y Schiavina, M. (2018). Analyzing spatiotemporal patterns of tourism in Europe at high-resolution with conventional and big data sources. Tourism Management, 68, 101-115. https://doi.org/10.1016/j.tourman.2018.02.020

Briguglio, L., Cordina, G., Farrugia, N. y Vella, S. (2009). Economic vulnerability and resilience: concepts and measurements. Oxford Development Studies, 37(3), 229-247. https://doi.org/10.1080/13600810903089893

Cheer, J. M. y Lew, A. A. (2018). Understanding tourism resilience: adapting to social, political, and economic change. En J. Cheer y A. A. Lew (Eds.), Tourism, resilience, and sustainability: Adapting to social, political and economic change (pp. 3-17). Routledge. http://bitly.ws/9Jg8

Cimoli, M. (2020). Recovery measures for the tourism sector in Latin America and the Caribbean present an opportunity to promote sustainability and resilience. Cepal. https://bit.ly/3gDpQFM 
Egan, D. J. y Nield, K. (2000). Towards a theory of intraurban hotel location. Urban Studies, 37(3), 611-621. https://doi.org/10.1080/0042098002140

Foo, L.-P., Chin, M.-Y., Tan, K.-L. y Phuah, K.-T. (2020). The impact of COVID-19 on tourism industry in Malaysia. Current Issues in Tourism, 1-5. https://doi.org/10.10 80/13683500.2020.1777951

Gasparino, U., Bellini, E., Del Corpo, B. y Malizia, W. (2008). Measuring the impact of tourism upon urban economies: A review of literature. Núm. 52.2008 [cuaderno de trabajo]. Fondazione Eni Enrico Mattei. http://bitly.ws/9Jfy

González, M. y León, C. J. (2020). La resiliencia del sistema turístico: salud, biodiversidad y clima. En M. Simancas, R. Hernández y N. Padrón (Coords.), Turismo pos-COVID-19. Reflexiones, retos y oportunidades (pp. 709-724). Universidad de La Laguna. https://doi.org/10.25145/b.Turismopos-COVID-19.2020

Gopalakrishnan, N. B., Peters, R. y Vanzetti, D. (2020). COVID-19 and tourism, assessing the economic consequences. United Nations Conference on Trade and Development. http://bitly.ws/9JfW

Gössling, S., Scott, D. y Hall, C. M. (2020). Pandemics, tourism and global change: a rapid assessment of COVID-19. Journal of Sustainable Tourism. https://doi.org $/ 10.1080 / 09669582.2020 .1758708$

Hardingham-Gill, T. (2020, 28 de julio). México y España, los países que serán más afectados por el impacto del COVID-19 en el turismo. CNN en español. https://cnn.it/2EhRvP3

Higgins-Desbiolles, F. (2020). Socializing tourism for social and ecological justice after COVID-19. Tourism Geographies, 22 (3), 610-623. https://doi.org/10.1080/ 14616688.2020 .1757748

Huitraleo, O. F., Calisto, L. L., Mansilla, M. E. y Gutiérrez, C. A. (2019). Factores de resiliencia ante vulnerabilidad en destinos y empresas turísticas: adaptación del método Delphi como instrumento de validación. Revista de Estudios Latinoamericanos sobre Reducción del Riesgo de Desastres, 3(1), 69-84. http://bitly.ws/9C3H 
Instituto Nacional de Estadística y Geografía (INEGI). (2014). Censos Económicos 2014. INEGI. http://bitly.ws/9C6P

Instituto Nacional de Estadística y Geografía (INEGI). (2015). Encuesta Intercensal 2015. INEGI. http://bitly.ws/9C8G

Instituto Nacional de Estadística y Geografía (INEGI). (2020). Directorio Estadístico Nacional de Unidades Económicas (DENUE). INEGI. http://bitly.ws/9C6S

loannides, D. y Gyimóthy, S. (2020). The COVID-19 crisis as an opportunity for escaping the unsustainable global tourism path. Tourism Geographies, 22(3), 624632. https://doi.org/10.1080/14616688.2020.1763445

Johnson, W. (2006). Policy responses to economic vulnerability. CDP Background Paper No. 9. ST/ESA/2006/CDP/9 [cuaderno de trabajo]. https://bit.ly/3I7Lhln

Malik, K. (2014). Human Development Report 2014: Reducing vulnerabilities and buildings resilience. United Nations Humand Development Program. http://bitly. ws/9C3y

Montaño, A., Ivanova, A. y Serrano, R. (2017). Desarrollo de destinos turísticos consolidados: Una visión desde la sustentabilidad y resiliencia. Gobierno del estado de Baja California Sur, H. XII Ayuntamiento de Los Cabos y Universidad Autónoma de Baja California Sur.

Organización para la Cooperación y el Desarrollo Económicos (OECD). (2020, julio). Coronavirus (COVID-19): SME policy responses. Tackling Coronavirus (COVID-19) contributing to a global effort. https://bit.ly/2Ck6Qgu

Organización Internacional del Trabajo (OIT). (2020). El impacto de la COVID-19 en el sector del turismo. https://bit.ly/2Qk4ZfD

Pitarch-Garrido, M. D. (2020). Turismo y vulnerabilidad territorial: capacidad de resiliencia de los diferentes modelos turísticos frente a la crisis pandémica del coronavirus en España. En M. Simancas, R. Hernández y N. Padrón (Coords.), Turismo pos-COVID-19. Reflexiones, retos y oportunidades (pp. 211- 
223). Universidad de La Laguna. https://doi.org/10.25145/b.Turismopos-COVID-19.2020

Proaño, W. P., Ramírez, J. F. y Pérez, I. (2018). Resiliencia del turismo ante fenómenos naturales. Comparación de casos de Cuba y Ecuador. COODES, 6(2), 225-240. http://coodes.upr.edu.cu/index.php/coodes/article/view/195

Rodríguez-Toubes, D. y Álvarez de la Torre, J. (2013). Vulnerabilidad del turismo y comunicación institucional ante desastres: estudio de casos. Redmarka, 2(11), 137-161. http://bitly.ws/9JeB

Secretaría de Salud de Jalisco (SSJ). (2020). Boletines de prensa marzo-julio 2020. https://ssj.jalisco.gob.mx/prensa/noticias

Secretaría de Turismo (Sectur). (s.f.). Oferta de servicios turísticos. https://www.datatur.sectur.gob.mx/SitePages/InventarioTuristico.aspx

Servicio de Información Agroalimentaria y Pesquera (SIAP). (2020). Anuario estadístico de la producción agrícola. https://nube.siap.gob.mx/cierreagricola/

Suárez Lastra, M., Valdés González, C., Galindo Pérez, M., Salvador Guzmán, L., Ruiz Rivera, N., Alcántara-Ayala, I., López Cervantes, M., Rosales Tapia, A., Lee Alardin, W., Benítez Pérez, H., Juárez Gutiérrez, M., Bringas López, O., Oropeza Orozco, O., Peralta Higuera, A. y Garnica-Peña, R. (2020). Índice de vulnerabilidad ante el COVID-19 en México. Investigaciones Geográficas, 0, 1-22. http:// doi.org/10.14350/rig.60140

Student, J., Lamers, M. y Amelung, B. (2020). A dynamic vulnerability approach for tourism destinations. Journal of Sustainable Tourism, 28(3), 475-496. https:// doi.org/10.1080/09669582.2019.1682593

Xu, H., Chen, F. y Dai, S. (2017). Disaster resilience of small businesses in Guanxian ancient town, Sichuan, China. En A. A. Lew y J. M. Cheer (Eds.), Tourism resilience and adaptation to environmental change: definitions and frameworks. (pp. 185-203). Routledge. 
Zhang, X. (2010). An investigation into the vertical coordination in tourism supply chains through buyback policy. En G. Q. Huang, K. L. Mak y P.G. Maropoulos (Eds.), Proceedings of the 6th CIRP-sponsored international conference on digital enterprise technology. Advances in intelligent and soft computing, vol. 66 (pp. 1331-1340). Springer. https://doi.org/10.1007/978-3-642-10430-5_102 